\title{
Performance Pay and the White-Black Wage Gap ${ }^{1}$
}

\author{
John S. Heywood \\ Department of Economics \\ Univeristy of Wisconsin - Milwaukee \\ P.O. Box 413 \\ Milwaukee, WI 53201 \\ Email: heywood@uwm.edu
}

\author{
Daniel Parent \\ Department of Economics \\ McGill University \\ 855 Sherbrooke St. W. \\ Montreal, Quebec, H3A 2T7 \\ E-mail: daniel.parent@mcgill.ca
}

August 2009

\footnotetext{
${ }^{1}$ We wish to thank Colin Green, Franque Grimard, Jenny Hunt, and Bentley MacLeod for comments on earlier drafts of this paper.
} 


\begin{abstract}
We show that the reported tendency for performance pay to be associated with greater wage inequality at the top of the earnings distribution applies only to white workers. This results in the white-black wage differential among those in performance pay jobs growing over the earnings distribution even as the same differential shrinks over the distribution for those not in performance pay jobs. We show this remains true even when examining suitable counterfactuals that hold observables constant between whites and blacks. We explore reasons behind our finding that performance pay is associated with greater racial earnings gaps at the top of the wage distribution focusing on the interactions between discrimination, unmeasured ability and selection.
\end{abstract}




\section{Introduction}

A major contribution of personnel economics has been to emphasize that performance pay helps identify and sort workers by productivity as well as eliciting additional effort and that, as a consequence, it generates greater earnings dispersion within the firm (Lazear (2000), Barth, Bratsberg, Haegeland and Raaum (2009)). On a broader scale, Lemieux, MacLeod and Parent (2009) argue that performance pay provides a channel that translates underlying changes in returns to skill into greater overall earnings inequality. They demonstrate that the growing incidence of performance pay combined with a substantial increase in the return to skills in those jobs account for a quarter of the growth in wage inequality over the 1980s and 1990s and nearly all of the wage inequality growth in the upper quintile of earnings. Thus, as they suggest, performance pay could be accommodating the growth in the underlying dispersion in marginal products generated by skill biased technical change (Juhn, Murphy and Pierce (1993)).

In this paper we examine the same time period separately identifying the influence of performance pay on the structure of black and white earnings in the United States. We first show that in both the March Current Population Survey (CPS) and the Panel Study of Income Dynamics (PSID), the white-black earnings gap in the private sector grows toward the top of the wage distribution. In approximately the upper quintile, something is definitely "pulling" the white distribution but not that of blacks. Focusing on the PSID which has information on pay methods, we next show that performance pay dramatically stretches the distribution of wages for whites but not for blacks. The consequences on the white-black wage differential are striking. Among those not in performance pay jobs and controlling for composition effects, the resulting "unexplained" racial differential shrinks almost monotonically when moving up the earnings distribution reaching essentially zero at the very top. Among those in performance pay jobs, controlling for composition does markedly reduce the gap but, nevertheless, the unexplained white-black wage differential increases in the upper end of the distribution reaching its largest at the very top.

Whatever is pulling the white distribution at the top is thus intimately related to performance pay. Reinforcing this pattern, the return to a performance pay job for blacks is smaller than for whites and decreases precipitously in the top quintile of the black wage distribution. For whites, the return to a performance pay job grows dramatically over the full range of the wage distribution. Possibly reflecting these returns, we find that high skill blacks appear far less likely to select performance pay jobs than do high skill whites. We provide additional evidence on selection by exploiting the presence of both methods-of-pay questions and the Armed Forces Qualifying Test in the 1979 cohort of the National Longitudinal Survey of Youth (NLSY). We also bring public sector workers into our analysis showing that while skilled whites appear disproportionately in the private sector and its

performance pay jobs, skilled blacks appear to remove themselves from the private sector into the more compressed wage structure of the public sector. 


\section{Discussion}

Our finding that the white-black differential doubles at the top of the performance pay distribution may flow from two potential sources. First, performance pay may allow a better match between marginal productivities and earnings. If so, the growth in the racial differential may reflect unmeasured ability differences at the top of the distribution that are not reflected in the time rate sector. Second, performance pay at the top of the distribution may lack transparency (relative to both the bottom of the performance pay distribution and the time rate sector) allowing employer and supervisory prejudice to more greatly influence earnings. While we cannot assign relative importance to these sources, we explore them empirically in the work that follows and use them to motivate the importance of our inquiry in this section. We summarize the conflicting nature of past evidence, argue for the necessity of moving beyond mean wage differentials and present an illustrative model in which performance pay at the top of the distribution makes pay setting less transparent and results in greater earnings discrimination. In the end, we suggest our evidence leaves scope for both explanations.

Past evidence on the role of performance pay on earnings differentials focuses exclusively on mean wage differentials and presents mixed results. Output based performance pay (such as piece rates, commissions and tips) reduces mean earnings differentials by gender (Heywood and Jirjahn (2002), Jirjahn and Stephan (2004)) and by race (Heywood and O'Halloran (2005); Fang and Heywood (2006)). Yet, Bronars and Moore (1995) find that such performance pay does not influence racial earnings differentials and others argue that performance pay based on subjective evaluations, as in a typical merit pay or bonus scheme, actually increases the latitude for supervisory prejudice (Marta and Town (2001)). Thus, Heywood and O'Halloran (2006) show that workers receiving individual annual bonuses tend to show larger racial earnings differentials than those receiving only time rates and Castilla (2008) shows not only that race influences appraisal ratings but that whites receive larger raises than blacks for equal ratings. Moreover, even what appears to be formulaic and not subjective may allow ample managerial latitude. Madden (2008) uses data from large brokerage firms to show that male managers provide female stockbrokers fewer "complementary inputs" (specifically, managers distribute a lower quality of account to female brokers) and that this explains their lower earnings from otherwise formulaic commission schemes. Indeed, Citigroup recently paid $\$ 33$ million to settle a gender discrimination suit charging them of just such client steering.

Importantly, not all discrimination arises from managerial preferences. If workers have contact with customers, it can be the customers' preferences that generate racial earnings differences (Kahn (1991), Holzer and Ihlanfeldt (1998)). Thus, workers receiving performance pay such as tips or commissions may have earnings that reflect these preferences generating racial earnings differentials. In short, the theory and evidence on the relationship between performance pay and racial earnings differentials might best be described as inconclusive.

We contribute, in part, by emphasizing that the influence of performance pay on racial earnings differentials is mischaracterized by a single mean estimate and its influence differs substantially across the earnings distribution. Thus, it may be the case that unmeasured ability is larger when 
measured ability is larger, at the top of the distribution. Alternatively, one might anticipate that performance pay schemes at the bottom of the earnings distribution tend to be more objective as in a simple piece rate while schemes at the top of the distribution tend to involve a broader but more subjective performance appraisal as in merit bonuses. Formulaic schemes are certainly recognized as inappropriate when workers have multiple and complex tasks as they are generate "adverse specialization" in those tasks providing the greatest rewards relative to effort costs (Baker (1992), MacDonald and Marx (2001)). The empirical evidence supports this showing that the alternative of a comprehensive performance appraisal becomes more likely when jobs are complex and involve many tasks (Brown and Heywood (2005)). Yet, such appraisals provide opportunities for both "evaluation bias," ranking equally productive workers differently due to race and "reward bias" paying the same ranking differently by race. As documented by Castilla, the current paradigm advocated by human resource management specialists, and increasingly followed in practice, separates performance appraisals from their use in pay decisions. His evidence suggests this separation makes merit pay schemes less transparent and less accountable causing him to claim merit pay schemes increase the likelihood of biased outcomes. ${ }^{1}$

\subsection{An Illustrative Model}

We now briefly illustrate how measured discrimination can be greater when performance pay at the top of distribution is less transparent and relies on less objective indicators. We imagine that workers and enforcement officials care about the true level of discrimination in workplace $i, D_{i}$. The best estimate of that discrimination is $\hat{D}_{i}=D_{i}+\varepsilon_{i}$. The error varies across technologies, managements and workforces and is distributed with mean zero and variance, $\sigma^{2}$. We assume that workers or enforcement officials report discrimination when they are $k$ percent certain that the true level of racial earnings discrimination, $D_{i}$ is greater than zero: $\hat{D}_{i}=z(k)$. Here $z$ represents the critical value of a one-sided test of statistical confidence level $k$ testing the null hypothesis that the true discrimination, $D_{i}$, equals zero. The critical value $z$, and hence the earnings differential indicating discrimination, depends on the quality of information, $\sigma^{2}$. The odds of being identified as a discriminator increase with both the extent of true discrimination and the quality of information (the smaller is $\sigma^{2}$ ).

Following Becker we imagine the employer values discrimination but wants to avoid the costs associated with discrimination such as the expected costs of detection. Thus, we consider the employer maximizing utility

$$
U\left(D_{i},\left(1-\pi_{i}\right)\right) \text { where } U_{1}, U_{2}>0 \text { and } U_{11}, U_{22}<0
$$

where $D_{i}$ is the extent of discrimination and $\pi_{i}$ is the probability of detection. As indicated, the detection probability itself depends on both the extent of discrimination, $D_{i}$ and $\sigma^{2}, \pi_{i}\left(D_{i}, \sigma^{2}\right)$ where $\pi_{1}>0, \pi_{2}<0$. We now trace out the consequences of the suggestion that at the top of earnings

\footnotetext{
${ }^{1}$ See MacLeod (2003) for a formal agency model with subjective evaluation in which prejudice is introduced.
} 
distribution the lack of transparency and accountability associated with performance pay decreases the quality of information.

Borrowing from Heywood and O'Halloran (2005) and Berzebat and Hughes (1990), we assume a uniform probability distribution and a constant elasticity of substitution utility function. Thus $f\left(\varepsilon_{i}\right)=\frac{1}{2} c$ for $\varepsilon_{i} \in[-c,+c]$ and zero otherwise. Given significance level $k$, the critical value is $z=2 c k-c$. In the upper end of the performance pay distribution the information quality gets worse and the dispersion (measured by $c$ ) increases for all $k>0.5$. The employer's probability of not being identified as a discriminator can be identified as

$$
\left(1-\pi_{i}\right)=\operatorname{Pr}\left[\hat{D}_{i}<z \mid D_{i}\right]={ }_{D_{t}} \int^{z} \frac{1}{2} d \varepsilon=k-\frac{D_{i}}{2 c}
$$

The utility function becomes

$$
U\left(D_{i},\left(1-\pi_{i}\right)=\alpha D_{i}^{\rho}+(1-\alpha) \pi_{i}^{\rho}\right.
$$

and substitution yields the optimization problem over $D_{i}$ :

$$
\max U=\alpha D_{i}^{\rho}+(1-\alpha)\left(k-\frac{D_{i}}{2 c}\right)^{\rho}
$$

The first order condition is

$$
\partial U / \partial D_{i}=\rho \alpha D_{i}^{\rho-1}-\rho(1-\alpha)(2 c)^{-1}\left(k-\frac{D_{i}}{2 c}\right)^{\rho-1}=0
$$

Rearranging yields the utility maximizing choice of discrimination $D_{i}^{*}$ :

$$
D_{i}^{*}=k\left[(2 c)^{-1}+2(c s)^{r}\right]^{-1}
$$

where $r \equiv 1 /(\rho-1)$ and $s \equiv \alpha(1-\alpha)$. Differentiating with respect to the information parameter $c$ yields:

$$
\partial D_{i}^{*} / \partial c=\frac{D_{i}^{*}}{C}\left[(2 c)^{-1}-r(2 c s)^{r}\right]\left[(2 c)^{-1}-(2 c s)^{r}\right]^{-1}>0
$$

The sign is positive if $r \leq 0$ which corresponds to the full range of allowable values of $\rho \in[-\infty, 1]$.

The comparative static indicates that if the presence of performance pay at the top of the distribution reduces the quality of information on earnings and productivity of workers (increasing c), the detection probability will decrease and the employer will respond by increasing the optimal earnings discrimination. This stands as an alternative to the suggestion that the larger racial gap at the top of the performance pay distribution reflects a closer alignment of ability and earnings. 


\subsection{Further Motivation}

Our result that among non-performance pay jobs the white-black earnings differential declines over the distribution of earnings certainly fits with received knowledge. Lang (2007) summarizes by saying "if there is discrimination in the labor market, it is concentrated at the lower end of the skill distribution. Black and white male college graduates have similar earnings." Moreover, in their work on the role of pre-market skills (as measured by the AFQT), Johnson and Neal (1996) and Johnson and Neal (1998) show that among those with scores more than one standard deviation above the mean, the black white difference in annual earnings for men falls to only five percent. ${ }^{2}$

Despite these general patterns, there remains emphasis on examining racial differences at the top of the distribution into which our work falls. This emphasis comes both from studies on racial earnings differences among the highly educated and from studies of the change in overall inequality. Among the former, Black, Haviland, Sanders and Taylor (2006) share a concern about pre-market factors but limit their examination to the college educated. They control for parent's educational attainment, for highest degree, for English language usage and for highly detailed measures of the field of highest degree. Using nonparametric matching techniques they find that that they can explain virtually all of the wage gaps between white men and Hispanic men and Asian men. Importantly, the same does not hold true for blacks. While they can find a near zero difference for black men with college-educated parents not born in the South, white-black differentials remain significant and often double digit for other college educated black males. In earlier work, Weinberger (1998) also examines the college educated controlling for detailed field of study, GPA and the exact institution attended. She reports a significant double-digit differential between black and white males and in related work reports a largely stable racial differential for the college educated over the 1980s and 1990s (Weinberger and Joy (2007)). Thus, while differentials may be larger among the less skilled, there remains concern that they also persist at the top of the distribution. ${ }^{3}$

Studies of the growth of inequality have emphasized the consequences on white-black earnings differentials. While Card and Lemieux (1994) cast doubt on a general connection between changing returns to skills and white-black wage differentials, Juhn, Murphy and Pierce (1991) and Card and Lemieux (1995) find that changes in skill prices reduced the earnings of blacks relative to whites. Reardon (1997) shows that the general inequality story of skill biased technical change may be particularly important in explaining racial inequality growth among highly skilled blacks and whites. Similarly, Rogers (2006) shows that the stretching (increased variance of wages) of the skill distribution during the 1980s explains the growth in within group white-black wage gaps at the top of that distribution. Related work by Bound and Freeman (1992) and by Chay and Lee (2000) document a widening in the black white earnings differential for young men over the 1980 s and

\footnotetext{
${ }^{2}$ Although Johnson and Neal (1998) are quick to emphasize that only five percent of black men in their sample score more than one standard deviation above the mean.

${ }^{3}$ We note that racial earnings differentials may be biased by the greater tendency of blacks to be among those with low earnings potential and so drop out of the labor force (Brown (1984), Neal (2004)). As this tendency is more muted at the top of the skills distribution, it is unlikely to greatly influence our finding of a large increase in the white-black differential over the last quintile for those on performance pay.
} 
show that it was largest among the college educated. ${ }^{4}$ The critical point to take away is that there remains interest in the white-black earnings differential among the highly skilled and that there exists a suggestion that increasing inequality may have an influence on that differential even if not on the differential in general.

We add value by showing that the method of pay is crucial in exploring these questions. The stretching of the white distribution relative to the black earnings distribution happens exclusively among those in performance pay jobs. Indeed, the white-black earnings differential grows over the distribution of earnings and is largest at the top of the distribution among those on performance pay jobs. Thus, for workers in performance pay jobs the summary provided by Lang (2007) seems inappropriate even as it correctly summarizes those not in performance pay jobs. Among those in performance pay jobs, the white-black earnings gap is largest at the top of the distribution. Among those in jobs without performance pay, the white-black earnings gap is largest at the bottom of the distribution.

Finally, we contribute to the evidence that performance pay causes ability sorting. In their case studies, Lazear (2000), Banker, Lee and Srinivasan (2000), and Sorensen and Grytten (2003) each find that sorting generates a large share (from one-third to more than half) of the productivity increase associated with performance pay. More generally, Curme and Stefanec (2007) show that workers on performance pay have higher standardized test scores, higher self-esteem and less fatalistic attitudes than do otherwise equal workers on time rates. Experiments confirm that those with greater risk tolerance, higher ability and more confidence tend to choose a performance pay scheme in the laboratory Dohmen and Falk (2001). While it seems clear from the literature that workers sort into performance pay to capture an ability rent, racial differences in this tendency have not been explored. As part of our discussion, we present evidence that such sorting is strongly present for white workers but far less common, perhaps absent, for black workers.

\section{Setting the Stage}

To motivate our main analysis which makes use of the PSID, we first show the variation in the raw $\log$ wage differential between blacks and whites across the wage distribution using the March Current Population Survey for the years 1976-1999. The hourly earnings measure derived from the March CPS, total annual earnings divided by annual hours worked, both for the previous calendar year, follows the same construction as the wage measure we use in the PSID. In principle, it should include all components of earnings, including variable pay components such as bonuses, commissions, etc. We show the white-black wage gap using the March CPS to demonstrate that the pattern observed in the PSID is not simply an artifact of that much smaller data set. ${ }^{5}$

Note that all the gaps shown in the figures below are obtained by first regressing the log wage on

\footnotetext{
${ }^{4}$ Couch and Daly (2002) identify a shrinking in the white-black wage gap over the 1990s but show that the decline was tempered by the changes in general inequality.

${ }^{5}$ We use individuals whose main job in the previous calendar year was in the private sector. Self-employed workers are deleted. We delete observations for which the wage is below $\$ 4.00$ or above $\$ 300.00$ in $\$ 2008$.
} 
a set of year dummies for employed individuals whose main job in the previous calendar year was in the private sector in order to net out yearly variations (although whether we do this or not makes no qualitative difference). We use the residuals of those regressions as our hourly wage measure.

As shown in Figure 1, the racial wage gap increases almost monotonically across the wage distribution. However, starting at approximately the 85th percentile, the white-black gap increases sharply. Clearly something is "pulling" the white wage distribution at the top but not the black wage distribution.

Next we perform the same exercise using the identical wage measure in the PSID. As can seen, the resulting Figure 2 is visually similar to Figure 1 although the gap shown in Figure 2 at the top end is even bigger than its corresponding value in Figure 1, and the gap measured using March CPS does not drop markedly between the 45 th and 85 th percentiles, as it does in Figure 2.

An initial goal of this paper is to show that the sharply increasing white-black wage gap at the top of the hourly earnings distribution computed using the March CPS-like measure is driven entirely by performance pay. Once we divide jobs into performance pay jobs and non performance pay jobs, we show that the white-black wage gap in non performance pay jobs actually decreases monotonically through most of the distribution. The next step is then to perform a counterfactual analysis to decompose the observed wage gap into a part that results from compositional effects and a part that results from "wage structure" effects. We also make use of a new unconditional quantile decomposition technique to assess the role played by key explanatory variables in both the compositional and the wage structure effects. We then follow with a discussion of the possible mechanisms underlying the relationship between wages and performance pay for white and black workers.

\section{Data}

While the bulk of our analysis is conducted using data from the PSID, we also provide additional evidence using the National Longitudinal Survey of Youth (NLSY). Both those data sets contain information on methods of pay although that information is rather crude, especially in the case of the PSID as described below.

\subsection{The Panel Study of Income Dynamics (1976-1998)}

The PSID sample we use consists of male heads of households aged 18 to 65 with average hourly earnings between $\$ 4.00$ and $\$ 300.00$ (in 2008 dollars) for the years 1976-1998, where the hourly wage rate is obtained by dividing total labor earnings by total hours of work, both reported retrospectively for the previous calendar year. ${ }^{6}$ Again, given our focus on performance pay, this wage measure based

\footnotetext{
${ }^{6}$ In the PSID, data on hours worked during year t, as well as on total labor earnings, bonuses/commissions/overtime income, and overtime hours, are asked in interview year $t+1$. Thus we actually use data covering interview years 1976-1999. Annual earnings were top coded at $\$ 99,999$ until 1982 (and not top coded since then), but only a handful of individuals were at the top code.
} 
on total yearly earnings, inclusive of performance pay, is preferable to "point-in-time" wage measures that would likely miss infrequent payments (e.g. bonuses) of performance pay.

Individuals who are self-employed are excluded from the analysis since our measure of performance pay based on receiving bonuses, commissions, or piece-rates is defined for employed workers only. For the moment we also exclude workers from the public sector since it is not clear what it means to pay workers for their productivity in a sector where decisions are not based on profit maximization. At the end of the paper, we bring public sector workers into the analysis to investigate possible connections between the respective wage structures of the private and public sectors. This leaves us with a total sample of 25,258 observations (6,928 for 896 black workers and 18,330 for 2012 white workers) for 3,053 workers. All estimates reported in the paper use the PSID sample weights. Note that we pool together all the observations for the 1976-1998 period when we perform our analysis of the white-black wage gap. Given that we are performing a distributional analysis, we need a reasonably large number of observations and cutting the data into separate time-periods to study possible changes over time dramatically reduces the number of wage observations for each sub-period. Nevertheless, we gain insight into the evolution of the process determining white-black wage differentials when we use the NLSY at the end of the results section.

\subsubsection{Identifying Performance Pay in the PSID $^{7}$}

We construct a performance-pay indicator by identifying whether or not a worker's total compensation includes a variable pay component (bonus, commission, or piece-rate). For all interview years we are able to determine whether a worker received a bonus or a commission over the previous calendar year through the use of multiple questions. First, workers are asked the amount of money they received from working overtime, from commissions, or from bonuses paid by the employer. ${ }^{8}$ Second, we sometimes know only whether or not workers worked overtime, and if they are working overtime in a given year, not the amount of pay they received for overtime. Thus, we classify workers as not having had a variable pay component if they worked overtime. Third, workers not paid exclusively by the hour, or not exclusively by salary, are asked how they are paid: they can report being paid commissions, piece-rates, etc., as well as a combination of salaried/hourly pay along with piece-rates, bonuses or commissions. Through this combination of questions, we can identify all non-overtime workers who received performance pay in bonus, commission, or piece-rate form.

\subsubsection{Defining Performance-pay Jobs}

We define performance-pay jobs as employment relationships in which part of the worker's total compensation includes a variable pay component (bonus, a commission, piece-rate) at least once during the course of the relationship.

\footnotetext{
${ }^{7}$ In this and the next subsection we provide the essential information underlying the identification and construction of our performance pay measure. Readers are referred to Lemieux, MacLeod and Parent (2009) for the full details.

${ }^{8}$ Note that the question refers specifically to any amounts earned from bonuses, overtime, or commissions in addition to wages and salaries earned.
} 
Since we use actual payments of bonuses, commissions or piece rates to identify performance-pay jobs, we are likely to misclassify performance-pay jobs as non-performance-pay jobs if some employment relationships are either terminated before performance pay is received, or partly unobserved for being out of our sample range. This source of measurement error is problematic because of an "end-point" problem in the PSID data. Given our definition of performance-pay jobs, we may mechanically understate the fraction of workers in such jobs at the beginning of our sample period because most employment relationships observed in 1976 started before 1976, and we do not observe whether or not performance pay was received prior to 1976. Similarly, jobs that started toward the end of the sample period may be performance-pay jobs but are classified otherwise because they have not lasted long enough for performance pay to be observed. We deal with that problem using the same adjustment method as that employed in Lemieux, MacLeod and Parent (2009). ${ }^{9}$

\subsection{Descriptive Analysis}

In Table 1 we report sample mean statistics for both types of jobs by race. Whites earn $31 \%$ more in performance pay jobs than in non performance pay jobs, for blacks the difference is only $12 \%$. This stands as the first indication that the influence of performance pay jobs may differ by race. Also, potential experience is somewhat smaller for blacks in performance pay jobs, although the difference is largely due to blacks being younger in performance pay jobs relative to whites. Another significant difference between whites and blacks is the change in the fraction of workers paid by the hour as one moves from non performance pay jobs to performance pay jobs. The increase in the percentage of white workers paid a salary in performance pay jobs is not mirrored for blacks, who are also much more likely than whites to be covered by a collective bargaining agreement regardless of the type of job. Both white and blacks workers in performance pay job workers are more educated and also work more annual hours than those in jobs without performance pay.

Unlike the NLSY, the PSID does not have a direct measure of achievement like the AFQT score but it does have information on family background. Johnson and Neal (1996) show that family background variables (parental education and occupational status) explain a significant fractionalthough by no means all-of the AFQT score. As shown in Table 1, individuals in performance pay jobs tend to come from families in which parents are more educated and also more likely to be in well-paid white collar occupations. However, and this will turn out to be important later when discussing differences between blacks and whites in terms of the selection process into performance pay jobs, the positive association between family background and performance pay jobs is more obvious in the case of white workers.

Our definition of performance pay job may mask differences across race in the detailed type of performance pay received by workers. In Table 2 we report the incidence of each type of performance pay by quantiles of the wage distribution for each race. The figures represent the fraction of workers receiving performance pay in a given year, not the fraction that ever received performance pay over

\footnotetext{
${ }^{9}$ Note that misclassification errors also have implications for the measured wage gap by type of jobs. More on that in the results section.
} 
the course of their employment relationship. While the numbers within categories appear too small for strong statistical inference, they paint an important picture. Piece rates are more common in the bottom of the distribution and in the bottom of the distribution they are paid disproportionately to blacks. Bonuses are more common in the top of distribution and in the top of the distribution they are paid disproportionately to whites. Commissions are more evenly spread through the distribution but are also concentrated among whites at the top of the distribution.

In Figure 3 we plot the overall incidence of performance pay jobs for whites and blacks by year (adjusted for the end-point problem mentioned above). White workers are clearly more likely to be in such jobs than black workers. Note, though, that the incidence for black workers increased sharply in the early 80's and has since been roughly parallel to the incidence for whites. Figure 4 shows where the discrepancy in incidence occurs in terms of location in the wage distribution, both for performance pay jobs using all components of variable pay, as well as for bonus pay jobs where only bonuses are used to construct the performance pay job indicator. The black and white incidences of performance pay jobs are more nearly similar in the bottom half of the distribution. The whites' incidence rises at an increasing rate from the middle to the top of the distribution while the increase at the top is considerably more modest for blacks. If performance pay jobs have an inequality enhancing effect, it is clear from Figure 4 that those jobs cannot be as significant a factor in explaining changes in inequality at the top of the black wage distribution as it is for whites. The same visual impression emerges if we look instead at the incidence of bonus pay jobs-jobs in which a bonus is received at least once over its duration. Figure 4 shows clearly that the discrepancy between whites and blacks as one reaches the top of the distribution is largely driven by bonuses. Indeed, all the qualitative conclusions from our counterfactual analyses below remain the same if we use only bonuses to define performance pay jobs. ${ }^{10}$

The next set of figures show kernel density estimates of the wage distributions. In Figures 5 and 6 we compare whites and blacks within the same job types whereas in Figures 7 and 8 we compare the wage distributions across job types within racial groups. Looking first at Figures 5 and 6 two things stand out. First, blacks are on average paid less regardless of whether they are in performance-pay jobs or not. Second, the black wage distribution in performance pay-jobs is "twin-peaked", suggesting that black workers at both ends of the distribution are much more likely to be pulled (or pushed) into performance pay jobs relative to whites. We should emphasize that we are simply plotting the observed wages without any sort of adjustment for the fact that the composition of the workforce might be very different across jobs and that such composition effects may be quite different for blacks relative to whites. In the next section, after outlining the methods used to perform such adjustments for differences in observables, we will show the adjusted distributions.

In Figures 7 and 8 we easily see that while white workers are paid more in performance pay jobs, the same cannot be readily observed for blacks. In addition, the inequality-enhancing effect of performance pay (whether through selection or incentive effects or a combination) is visually more obvious for whites. Specifically, there is little visual evidence that blacks at the top of the

\footnotetext{
${ }^{10}$ Those are available upon request
} 
performance pay job wage distribution are paid more than at the corresponding position in non performance pay jobs.

Turning to the white-black wage gap by percentile, Figure 9 shows that the raw gap for performance pay jobs actually exceeds that for non-performance pay jobs everywhere except in the bottom percentiles where the gaps are essentially the same. The gap in performance pay jobs follows a mild inverted $\mathrm{U}$ shape until about the 80 th percentile before rising sharply at the top end of the wage distribution. The contrast is striking when compared to non performance pay jobs where the whiteblack wage gap basically decreases throughout. In fact, the racial wage gap is the largest at the very top of the performance pay distribution while it is the smallest at the top of non performance pay distribution. Figure 9 strongly suggests that the increase in the white-black wage gap at the top end shown using the March Current Population Survey is driven entirely by performance pay.

Figure 10 shows striking differences in wage differentials between types of jobs within racial groups. For whites, the performance pay job premium is roughly constant until one reaches the 60 th percentile, after which it rises in a convex fashion. For blacks the pattern is very different: the gap decreases until the 50th percentile, at which point blacks are paid roughly the same in either type of job. The gap then moves up only to fall dramatically over the last quintile. These figures make clear that performance pay is associated with "stretching" the wage distribution for white workers at the top relative to what happens to workers in non performance pay jobs and that this is simply not true for black workers. For whatever reason, performance pay does not appear to a play the inequality enhancing role at the top of the black wage distribution that it does for whites. Again, given the

purely descriptive nature of these figures, it is not clear at this point whether this results merely from different selection effects for blacks relative to whites or from true wage structure effects. We turn to these compositional issues next.

\section{Adjusting for Composition Effects}

To account for the fact that the distribution of observable characteristics may be very different across both races and job types, we make use of an extension of the methodology developed in DiNardo et al. (1996) (henceforth DFL). Given the nature of our problem, namely the analysis of wage gaps between two groups of workers observed in either performance or non performance pay jobs, we need to extend the DFL method to allow for the additional dimension of choice (types of jobs). Details of the DFL methodology and the extension we use are relegated to Appendix 1. Note also that throughout we reweight the wage distribution of white workers to make it similar to that of blacks. We do not perform the reverse exercise of reweighting the black distribution to make it look like the white distribution. Although equally valid in principle, we would face a common support problem similar to that in Barsky, Bound, Charles and Lupton (2002) in their analysis of the relationship between wealth and earnings for blacks and whites: although it is not difficult to find white workers comparable to blacks at any point of support of the distribution of $X^{\prime} s$ for blacks, it is more difficult 
to find black workers who are comparable to whites at the top end. ${ }^{11}$

In Figures 11 and 12 we reproduce the wage gaps shown in Figure 9 except that we adjust for composition effects by reweighting the distributions of wages in both types of jobs such that the distribution of observables for white workers is the same as that for black workers. Note that we show three counterfactuals, one which we call "pre-market" adjusting only for educational attainment and census region of residence, one without parental education and father's occupational status that adds all our other controls and one that adds both all the other controls and the two background variables. ${ }^{12}$ As mentioned earlier, Johnson and Neal (1996) show that those family background variables account for a substantial fraction (up to 30\%) of the white-black gap in AFQT scores. Assuming selection on ability, one would expect those controls to play a substantial role, possibly more so in performance pay jobs than in non performance pay jobs, as the former may more closely tailor compensation to productive ability.

Quite clearly, composition effects matter in both types of jobs. In fact, after controlling for composition, the racial wage gap in the top half of the non performance pay job wage distribution appears largely absent. This is particularly true once we control for family background variables. While there remains a sizable gap in performance pay jobs, composition plays a large role. Roughly $65 \%$ of the raw wage gap at the top end of the wage distribution for performance pay job workers reflects composition effects. Moreover, when controlling for family background the gap approaches zero between roughly the 70 th and 90 th percentiles. Yet, in the top $10 \%$ a very sharp increase remains bringing the gap back to a surprisingly larger $30 \%$.

Figures 11 and 12 suggest strongly that family background plays a larger role in explaining the gap in performance pay jobs than in non performance pay jobs over a wide range of the upper half of the distribution. Still, it does not tell us whether selectivity according to ability operates differently for blacks than for whites. One way to examine that directly recomputes the wage gap between performance pay job workers and other workers by race, as shown in Figures 10, but this time controls for composition by adjusting the distribution of observed characteristics of workers in performance pay jobs such that it matches that of workers in non performance pay jobs. Figures $13 \mathrm{~A}, \mathrm{~B}$ present the results. Looking first at the actual vs the counterfactual wage gaps for black workers we can see that composition effects matter a lot over a wide range of the wage distributions. However, once we reach the very top there is little evidence that black workers in performance pay jobs are much different along observable dimensions than those in non performance pay jobs. The same cannot be said of white workers, as seen in Panel B of Figure 13. For white workers, composition effects remain roughly of the same magnitude throughout the distribution, and family background variables add very little.

\footnotetext{
${ }^{11}$ For example while the range in years of education is the same for both whites and blacks there are few blacks with 16 or more years of education in performance pay jobs (231 observations) relative to whites (2224) but a lot of observations for those with just a high school degree (1218 for blacks and 3254 for whites). Add to this that the support is multidimensional (e.g. workers with 17 years of education in management positions in the financial sector), and the comparability problem gets compounded.

${ }^{12}$ We recognize that it may be a stretch to categorize region of residence and education as "pre-market" factors. The idea is simply to develop from a parsimonious specification to our most complete specification. An alternative would have been to start with just the family background variables.
} 
Coming back to Figures 11 and 12, there is evidence that composition effects increasingly matter relative to "wage structure" effects (the part of the wage gaps left unexplained by adjusting for observables) in the case of performance pay jobs, but not for non performance pay jobs. To see this more directly, in Figure 14 we plot $95 \%$ confidence intervals of both the composition as well as the wage structure effects resulting from the DFL decomposition. Although wage structure effects are more important than composition effects in the low-to-middle quantiles of the wage distribution for performance pay jobs, the relative importance of composition effects increases dramatically as we move toward the top once family background variables are included. For non performance pay jobs, not surprisingly, there is no role left for wage structure effects once we get beyond the middle of the distribution. In addition the relative contribution of composition effects is roughly constant whether we include family background variables or not.

The upshot we take from Figures 11 and 13A,B is that, for some reason, the ability of performance

pay jobs to "stretch" the distribution at the the top end through a wage structure effect, one of the key results in Lemieux, MacLeod and Parent (2009), is essentially a whites-only phenomenon. There is little evidence of an inequality-enhancing effect of performance pay for blacks at the top of the distribution. One reason suggested from Figures 13A, B is that the black skill distributions in performance pay jobs and non performance pay jobs are roughly similar at the top end of the earnings distribution while they differ dramatically for white workers. Still, we should not overlook the fact that up to the 90th percentile, controlling for composition effects-including family backgroundaccounts for the bulk of the white-black gap in performance pay jobs.

\section{Which Variables Matter More in Generating the Composition and Wage Structure Effects?}

Having computed both parts of the total wage gap, we now examine which variables or set of variables explain the composition and the wage structure effects. Although parsing out the influence of each observable characteristic is straightforward to do in the case of means using the usual Blinder-Oaxaca decomposition, until recently the same could not be said in the case of other distributional statistics of interest such as the median wage gap.

\subsection{An Unconditional Quantile Regression Approach to Assess the Effect of Observables}

One key feature of the Blinder-Oaxaca decomposition method is that one can average out the conditional-on- $X$ wage gaps by the law of iterated expectations, and thus get a population parameter, i.e. $E(E(Y \mid X))=E(Y)$. If one is interested in wage gaps at various quantiles of the wage distribution, this averaging out property does not hold. For example, the expectation of the conditional median (or of any other quantile) does not produce the median of the marginal distribution. Consequently, using standard conditional quantile regressions to examine the effect of covariates at different quantiles does not allow to recover the unconditional (in the sense of having "integrated 
out" the $X^{\prime} s$ ) parameter of interest. A new procedure proposed in Firpo, Fortin and Lemieux (2009) (FFL) provides a method for computing such unconditional quantiles and provides estimates of the effects of each individual covariate at different parts of the wage distribution. Their method rests on using the influence function as the dependent variable in a linear regression framework. ${ }^{13}$ In the case of a quantile $q(\tau)$, its recentered influence function $R I F_{i}$ for observation $w_{i}$ is given by

$$
R I F_{i}=q(\tau)+\frac{\left[1\left(\left(w_{i} \geq q(\tau)\right)-(1-\tau)\right]\right.}{f(q(\tau))}
$$

where $f()$ is the density and 1() is the indicator for whether the wage observation is at or above the quantile $q(\tau)$. The idea of recentering the $R I F$ by adding $q(\tau)$ is simply that since $E\left(\left[1\left(\left(w_{i} \geq\right.\right.\right.\right.$ $q(\tau))-(1-\tau)])=0$, the expected value of the recentered $R I F$ will be $q(\tau)$ itself. FFL show that this zero-expectation property extends to the conditional-on- $X R I F$. Thus, in practice, running a regression of $R I F_{i}$ on $X_{i}$ amounts to running a linear probability model for whether the observed wage is above the quantile of interest. The only difference with the linear probability model is that the coefficients need to be divided by the density evaluated at that quantile. ${ }^{14}$

Although readers are referred to the paper by Firpo, Fortin and Lemieux (2009) for details, Figure A1, based on a similar one in Boudarbat and Lemieux (2007) provides the intuition behind the procedure. Suppose one is interested in the median wage gap between whites and blacks. Note that while standard procedures cannot be used to decompose the median wage gap, it is straightforward to decompose the probability gap $\operatorname{Prob}(B)-\operatorname{Prob}(W)$, where $\operatorname{Prob}(W)$ represents the fraction of white workers earnings less than the median for blacks $q(.5) \_B$, by running a linear probability model for the probability that the wage observation is above $q(.5) \_B$ for each group. The picture makes clear, though, that there is a connection between the probability gap and quantile gap $q(.5)_{-} W-q(.5)_{-} B$. In fact the ratio of the two is simply the slope of the cumulative distribution function-the density. Hence one can transform the probability gap into a quantile gap by dividing the linear probability model coefficients throughout by an estimate of the density.

In comparing the wage distributions of whites and blacks in performance pay jobs (for example), we first reweight the distribution of workers in one group to control for composition. This first step allows us to separate composition effects from wage structure effects. In the second step, we use the recentered influence function regression approach to obtain the contribution of each covariate to both the composition and the wage structure effects.

To fix ideas, consider the observed median wage gap between whites $(W)$ and blacks $(B)$ in performance pay jobs:

$$
\Delta_{.5} \equiv q_{W}(.5)-q_{B}(.5)
$$

\footnotetext{
${ }^{13}$ The influence function provides a measure of how robust a distributional statistic is to outlier observations. For example, in the case of the mean $\mu=E\left(Y_{i}\right)$ the influence function is $Y_{i}-\mu$.

${ }^{14}$ The FFL decomposition procedure, which is based on providing a linear approximation to a non-linear functional of the distribution, only provides a first-order approximation to the true composition effects, irrespective of whether one uses a linear probability model or not. Consequently, the extent to which the approximation is imperfect (including the choice of the linear probability model) will be reflected in the approximation error. We report those below.
} 
By using the extended DiNardo, Fortin and Lemieux (1996) reweighting methodology described in Appendix 1, one can construct a counterfactual wage distribution, for example the distribution of wages for white workers in performance pay jobs if they had the same distribution of characteristics as blacks. This provides us with a counterfactual median wage $q_{c}(.5)$ :

$$
\Delta_{.5}=\left(q_{W}(.5)-q_{C}(.5)\right)+\left(q_{C}(.5)-q_{B}(.5)\right)
$$

The first pair of terms gives the part of the wage gap due to composition effects (the white workers' return to skill function is held constant) white the second pair provides us with the wage structure effect (the $\mathrm{X}^{\prime}$ 's are held constant but not the returns to skill functions). Labelling the part due to composition $\Delta^{X}$ and the part due to wage structure effects $\Delta^{g}$ we thus have:

$$
\Delta_{.5}=\Delta_{.5}^{X}+\Delta_{.5}^{g}
$$

Given this breakdown of the overall wage gap, we then use the recentered influence function regressions to further allocate the composition and the wage structure effects to each individual covariate. In practice, for each quantile $\tau$ of interest this simply amounts to:

1. Run separate RIF regressions for $q_{W}(\tau), q_{C}(\tau)$, and $q_{B}(\tau)$.

2. Perform the usual Blinder-Oaxaca decomposition for each part of the wage gap measured at various quantiles. For example, in the case of the median wage gap represented by equation(1), one decomposition is performed for $\Delta_{.5}^{X}$ and another for $\Delta_{.5}^{g}$.

\subsection{Results}

\subsubsection{Workers in Performance Pay Jobs}

In Table 3 we report the results from the FFL decomposition of the white-black wage gap outlined above. Note that we report only the results from the Blinder-Oaxaca exercise which is based on the coefficients of the RIF regressions, and not the RIF regression coefficients themselves, unless specific ones are worth discussing. For example, the overall composition effect in performance pay jobs at the median is allocated to the various X's by using the $\beta^{\prime} s$ estimated for whites and multiplying those by the difference in the average value of each corresponding $X$ between the actual values and the counterfactual values for whites. As for the wage structure effect, we use the difference in $\beta^{\prime} s$ between whites and blacks and multiply by the average of the corresponding $X^{\prime} s$ for blacks.

We show two sets of results in Table 3 , one set without the variables related to family background and the other including it. One unappealing feature of any decomposition, whether it is the usual Blinder-Oaxaca or the DFL methodology, is the strong assumption of selection on observables. This is perhaps even more of an issue in the case of performance pay. The idea of leaving out and then including family background variables is to see whether the results are qualitatively affected by the addition of those markers of some of the unmeasured dimensions of the workers. As we will see below, including family background does allow us to attribute a bigger share of the observed wage 
gap to composition effects at the expense of wage structure effects, thus indicating that unmeasured ability does matter in determining who is observed in performance pay jobs. Yet, adding family background controls does not result in reversing any of the conclusions that could be drawn from performing the decomposition without including them.

Looking first at Panel A of Table 3, it is clear that differences in educational attainment and potential experience play a substantial role in explaining the white-black wage in performance pay jobs. In fact, having more experience and education plays an increasingly larger role as we move towards the top of the distribution. This is true whether or not we control for family background. The effect of those family background variables is somewhat harder to interpret, although the general tendency is for an increasingly larger role towards the top. For example, there is little evidence that having a father who was/is a professional can account for a significant part of the gap at the top end; in fact controlling for that effect tends to make the gap bigger, not smaller. The reverse is true for having a father in management occupations and is larger at the top than at the bottom.

In terms of the accuracy of the linear approximation, from the approximation error reported at the bottom of the panel we can see that between 72 and 99 percent of the total composition effect is accounted for by the model (in absolute value).

Turning to wage structure effects (the $\beta^{\prime} s$ ) shown in Panel B of Table 3 , the results show that differences in the returns to education and experience play a much larger role as we reach the top of the black and white wage distributions. In fact the magnitude of the effects is so large that it overexplains the differences by a substantial margin. This "overshooting" is to a large extent offset by the differences in the contribution to the wage structure effects of the local unemployment rate on the wages of blacks and whites at the top of the distribution. ${ }^{15}$ Recall that the differential effects of the county unemployment rate is computed as the difference between the coefficients associated to the unemployment rate between white workers and black workers times the average unemployment rate for blacks in performance pay jobs. For example, the coefficient of the RIF regression estimated at the 95 th percentile is -0.0581 for whites compared 0.0061 for blacks. Hence the wages of black workers in performance pay jobs are much less sensitive to fluctuations in local labor market conditions in the top decile of the distribution than is the case for whites while the reverse is true in the bottom half: at the 20th percentile the coefficient associated to the county unemployment rate is -0.0156 for whites compared to -0.0626 for blacks.

The large differences in the returns to educational attainment and experience at the top of the distribution could result from some combination of both unmeasured ability and discrimination. We know that the composition effects are largely driven by education and experience and one dimension of unmeasured ability could be that blacks receive a lower quality of education. In this view, if black workers become more educated and receive education of more similar quality, the racial wage gap in performance pay jobs would decrease. Yet, Panel B of Table 3 shows that the racial difference in returns to education and experience rises quite sharply in the top decile of the performance

\footnotetext{
${ }^{15}$ Note that leaving out the unemployment rate does not make a qualitative difference to the magnitude of the coefficients associated to the other covariates except for the regression constant. Similarly, leaving out all the other covariates does not qualitatively change the magnitude of the impact of the unemployment rate.
} 
pay job wage distribution and it might stretch credibility to contend that the quality of education suddenly diverges above the 90th percentile. While differences in educational quality are far from the only dimension of unmeasured ability, it clearly remains possible that performance pay jobs at the top of distribution could be associated with greater latitude to discriminate by either managers or customers.

\subsubsection{Workers in Non-Performance Pay Jobs}

Turning to Panel A of Table 4, the first thing to note is that while having at least a B.A. degree matters, there is little evidence that it matters more at the top of the distribution than it does in the middle. This is also true for potential experience, whose contribution to the overall composition effect is negligible throughout. This indicates that, indeed, performance pay does seem to be associated more with having a highly skilled group of workers relative to non performance pay jobs. Further evidence of this is provided by looking at the contribution of parental education to the composition effect. We can see that contrary to the case of performance pay jobs, having more educated parents seems to matter more in terms of accounting for part of the composition effect in the bottom half of the distribution than it does at the top.

Turning to Panel B and the contribution of the covariates to the wage structure effects, perhaps the most striking result is the change relative to performance pay jobs in the differential impact of the local unemployment rate. While, as in the case of performance pay job workers, there is evidence that wages in the bottom half of the distribution are more responsive to local labor market conditions for blacks than for whites, there is none of the dramatic reversal at the top that we observe for performance pay job workers. In fact the wage of black and white workers are equally invariant to fluctuations in the conditions of the labor market (the coefficient for whites is equal -0.0059 compared to -0.0050 for blacks). This lack of sensitivity of black wages to fluctuations in local labor market conditions, which would translate into a higher total compensation when the times are good in performance pay jobs, could explain why performance pay jobs may not be as attractive to skilled black workers as they are to skilled white workers. As illustrated in Figure 13, performance pay jobs simply do not seem to be able to pull the top end of the wage distribution for black workers, contrary to what we observe for white workers. One reason for it is that there is no strong evidence that skilled blacks at the top end are selected into performance pay jobs to a greater extent than they are in non performance pay jobs. This pure selection effect would in itself drive up the wage gap between white and black workers in performance pay jobs as one reaches the top end.

Summarizing the results from our unconditional quantile regression analysis, we find that educational attainment, labor market experience, as well as family background clearly matter more in performance pay jobs than in other jobs in terms of accounting for the white-black wage gap. This is true both for their respective contributions to the composition effects as well as to the wage structure effects. We view the former as evidence that selection on skills is a key factor determining who works in performance pay jobs, while the latter is strongly suggestive that for the same level of 
skills the return to those skills is lower for blacks.

Clearly we are limited in terms of what we can infer about the driving forces behind the fact that the inequality-enhancing effect of performance pay appears to be a strictly white phenomenon. Discrimination could be a factor. At least it can help explain why the returns to education and experience are lower for blacks than for whites in performance pay jobs. However skills themselves also can explain a significant portion of the wage gap.

\subsection{Further Evidence on Selectivity into Performance Pay}

\subsubsection{Performance Pay in the NLSY}

As pointed out above, it seems as though more skilled black workers are not disproportionately attracted to performance pay jobs relative to whites. We can gain some further insight into this by exploiting the presence of the AFQT test score in the NLSY in addition to questions on pay methods which allow us to construct an indicator for performance pay jobs the same way we do using the PSID. ${ }^{16}$ Unfortunately the questions on pay methods run from 1988 to 1990 and then from 1996 onward. This considerably exacerbates the misclassification problem discussed in the data section. As a consequence, any difference between workers in performance pay jobs and those in non performance pay jobs will be understated. That, as well as the fact that the NLSY follows a narrowly defined cohort, explains why we chose to focus on the more consistent PSID to perform the analysis. Still, the presence of the AFQT scores provides an opportunity to see the extent to which whites may be more likely to select into performance pay jobs as one moves to the top of the skill distribution. It also allows us to see whether the patterns documented above using the PSID hold for this younger age group.

In Figure 15 we plot the raw AFQT score percentiles by types of jobs for both blacks and whites. The visual impression is quite striking and is strongly supportive of the evidence reported using the PSID. As Panels A and B show, there is little evidence that blacks with better AFQT results systematically select into performance pay the way that white workers do. In fact, it is interesting to note that the shape of the AFQT distribution in performance pay jobs for whites looks similar to Figures 2 and 3 in Johnson and Neal (1996). Those figures, also from the NLSY, showed a clear single peak of the black distribution to the left of a clear single peak for the white distribution of AFQT scores. While the single peak to the left is clear for blacks in both types of jobs, the peak to the right for whites appears to be largely driven entirely by those in performance pay jobs. Quite clearly, performance pay jobs are the main driving force behind the fact that the white distribution is left-skewed.

As an additional piece of evidence, notwithstanding the fact that the misclassification problem

\footnotetext{
${ }^{16}$ The NLSY asks explicitly about pay for performance in the $1988,1989,1990,1996,1998$ and 2000 waves of the panel. A first question is asked about whether part of the worker's pay is based on job performance. Note that workers are asked to ignore profit sharing (for which there is a separate question). Then they are asked to identify whether it takes the form of piece rates, commissions, or bonuses. As in the case of the PSID, we only focus on males. We also impose a couple of additional sample restrictions similar to those used by Gibbons et al. (2005). As in the case of the PSID, we classify a job as a performance pay job when the worker reports performance pay at least once on this job.
} 
is magnified in the NLSY, in Figure 16 we show the white-black hourly earnings wage gap in both types of jobs. Note that for comparability purposes across data sets we use total annual earnings divided by annual hours. As with the March CPS, we believe this wage measure is much more likely to include all components of pay, as opposed to a point-in-time measure.

The main pattern of a sharply increasing wage gap as one reaches the top of distribution emerges once again. On the other hand, the decline in the white-black wage gap in non performance pay jobs that we see in the PSID is much less apparent here. In fact the white-black wage gap is roughly constant over much of the wage distribution, except perhaps at the very top where it rises. However, we believe that one should be cautious in interpreting the different visual impression for non performance pay job workers suggested by Figure 16 relative to what we see in Figure 9 with the PSID. As mentioned above, the shorter NLSY panel exacerbates the misclassification problem. In Appendix 2 we describe a simple, empirically tractable, measurement framework in which we make more concrete the nature of the biases imparted by wrongly classifying performance pay jobs as non performance pay jobs. We show that under reasonable assumptions, the white-black wage gap in non performance pay jobs is overstated and the magnitude of the overstatement increases as one approaches the top end of the distribution.

Overall, we view the descriptive evidence provided in Figure 16 as broadly agreeing with what we show using the PSID. Interestingly, given that the NLSY focuses on a generally younger cohort of workers than those surveyed in the PSID, it also provides a view as to whether there has been a change over time in the patterns of the wage gaps in both types of jobs. It would appear that the key finding that performance pay has been the main driving force behind larger racial wage gaps at the top of the distribution is an empirical regularity and not the consequence of some special feature of the PSID.

\subsubsection{The Wage Effect of Performance Pay}

To provide more direct evidence on selection into performance pay jobs, we estimate separate log wage regressions for blacks and for whites on the performance pay job dummy and the same set of variables used in our counterfactual analysis. We examine the change in the performance pay coefficient for blacks compared to whites in going from OLS to fixed-effects estimates. This change provides direct evidence regarding selection on fixed unobservables.

Looking at Table 5, there is little difference between the OLS and fixed-effects coefficient for blacks. If anything, the estimated coefficient increases although it remains imprecise. Clear evidence of positive selection emerges for whites as the fixed-effects coefficient is markedly smaller. This stands as a further indication that the nature of selection differs for blacks and whites.

In total, the results of this subsection indicate substantial differences by race in the process governing who selects into performance pay jobs. Our counterfactual analysis clearly showed that even controlling for composition, there exists a significant racial difference in the returns to characteristics associated with productivity-education and experience-in performance pay jobs. This was especially evident at the top of the earnings distribution and corresponds with high skill blacks being less 
eager than high skill whites to enter performance pay jobs. Seen this way, our evidence of a sharply increasing raw white-black wage gap at the top of the performance pay distribution results both from lower returns to skills for blacks and from high skill blacks being less likely to select performance pay jobs.

\subsubsection{The Choice of Working in the Public vs the Private Sector}

A key reason for focusing on the private sector is the cleaner connection between productivity and pay resulting from the profit maximization motive. Yet, workers may also elect to work in the public sector. If the selection process governing this choice differs across race, there may be important consequences for the measured private sector wage differentials. While showing some variation across time and level of government, the white-black earnings differential is generally much smaller in the public sector during our study periods (Smith (1980) and Heywood (1989)). Moreover, the public sector is recognized as having a far more compressed wage structure with far less individualization of earnings (Bender (2003) and Borjas (2002)). This compression has grown over our study period and, according to Borjas (2002), is responsible for the public sector finding it increasingly difficult to attract and retain high skill workers. Thus, high skill white workers may avoid the public sector because of this compression and the lack of individualization of earnings. At the same time, our earlier evidence makes it unclear whether or not high skill blacks will follow suit.

To investigate these issues we add to our base sample of private sector workers all those working in the public sector. This results in adding 2298 observations for 445 black workers and 4326 observations for 679 white workers. The relative importance of black workers in the subsample of public sector workers provides a first indication of the importance of that sector for blacks.

In Figure 17 we show the "within-race" wage gap between private and public sector workers. We show both the raw wage gap and the counterfactual one if workers in the private sector had the same distribution of characteristics as those in the public sector. Since we want to examine how measured skills may be rewarded differently across sectors, our counterfactual wage gaps make use of only education, potential experience, employer tenure, and interactions between those three markers of productive characteristics. ${ }^{17}$ While white workers in roughly the top 20 percentiles earn more in the private sector, and increasingly so, the same is not true for black workers at the top end. For them, the raw wage gap in the top 20 percentiles is around zero. If we look at the counterfactual wage gaps, we can see that white private sector workers would do even better relative to their public sector counterparts if they had the same distribution of skills. ${ }^{18}$ On the other hand, controlling for composition basically leaves unchanged the wage gap for blacks at the top end. High skill blacks are paid about the same whether they work in the public or the private sector while high skill whites are

\footnotetext{
${ }^{17}$ What we have in mind is that wage setting practices in the public sector-the "pay scales"- rely heavily on those worker attributes. As it turns out, whether we also include marital status, occupations, collective bargaining, and interactions between those and education and experience does not make much of a difference qualitatively. Of course we have to exclude industries to avoid having a prefect predictor of public sector status in the construction of our DFL weights.

${ }^{18}$ While $9.5 \%$ of black workers hold at least a B.A. degree in the private sector, $12.4 \%$ do so in the public sector. For whites, the corresponding figures are $22.7 \%$ and $43.4 \%$.
} 
paid much more in the private sector. In short, the general results on earnings and sorting presented by Borjas (2002) apply only to whites. The absence of a sizable wage gap for blacks increases the likelihood that they will enter the public sector contributing to creating a relative void at the top end of the black skill distribution in the private sector and exacerbating wage differences between white and blacks workers.

In Figure 18 we plot the white-black wage gap in the public sector. While the raw wage gap is positive and substantial, it remains relatively constant across the distribution. There is no evidence of the sharp increase in the white-black wage differential at the top as in the private sector. More importantly, once we control for composition, there is also no evidence of any positive difference between white and black workers' wages in the public sector. We view this as being consistent with more rigid pay practices in that sector, with less room for discretion. This rigidity appears to attract high skill blacks but not high skill whites. ${ }^{19}$

We now investigate whether or not the unmeasured (by the econometrician) worker characteristics differ by race between the two sectors. To do so we estimate a simple error component model separately for each group/sector. Letting $l w_{i t}$ be the log hourly wage of worker $i$ at time $t$, for the public sector workers we have:

$$
l w_{i t}^{\text {public }}=X_{i t} \beta^{\text {public }}+\alpha_{i}+\varepsilon_{i j t}^{\text {public }},
$$

while the log-wage equation for the private sector workers is

$$
l w_{i t}^{\text {private }}=X_{i t} \beta^{\text {private }}+d \alpha_{i}+\varepsilon_{i j t}^{\text {private }}
$$

where $X_{i t}$ is the set of observable characteristics with a conformable parameter vector $\beta, \alpha_{i}$ is the unmeasured component of variance associated with worker $i$ (with factor loading $d$ for private sector workers), and $\varepsilon_{i t}$ is an idiosyncratic residual component. Note that we normalize to one the factor loading associated with the public sector. To estimate $\left(\sigma_{\alpha}^{2}, d^{2} \sigma_{\alpha}^{2}, \sigma_{\varepsilon}^{2}(\right.$ public $)$, and $\sigma_{\varepsilon}^{2}($ private $)$ ), we take the residuals of the regression of $l w_{i t}$ on the observables $X_{i t}$ and we then estimate the variance components by fitting regression models to all the cross-products of the residuals for the same individual. Implicit in the formulation of the error structure is the assumption that the distribution of the worker component $\alpha_{i}$ is the same in both sectors. It is this homogeneity that allows identification of the factor loading $d$, the extent to which unmeasured skills are rewarded differently in the private sector. ${ }^{20}$ Otherwise we would potentially mix workers located at different parts of the skill distribution. In essence, just as it is important to control for composition by reweighting the

\footnotetext{
${ }^{19}$ Interestingly, the desire to reduce the rigidities in the compensation practices of the federal government led to the Civil Service Reform Act of 1978 creating a pay-for-performance system whose goal was to more explicitly tie performance to financial incentives instead of the common practice of having salary increases based on length of service only (Milkovich and Wigdor (1991)). The book edited by Milkovich and Wigdor provides a comprehensive assessment of the potential for merit pay in the civil service as well as of its potential pitfalls.

${ }^{20}$ In effect we estimate (and report) $\widetilde{\sigma_{\alpha}^{2}} \equiv d^{2} \sigma_{\alpha}^{2}$ and simply test whether $\widetilde{\sigma_{\alpha}^{2}}=\sigma_{\alpha}^{2}$, which is sufficient for our purpose. Taking the ratio of $\widetilde{\sigma_{\alpha}^{2}}$ estimated with private sector workers to $\sigma_{\alpha}^{2}$ estimated with public sector workers would identify $d^{2}$.
} 
distribution of observables in our counterfactual exercises, here we control for composition by using the sub-sample of workers observed in both sectors in the course of their careers. ${ }^{21}$

The results are reported in Table 6. Looking first at Panel A, the return to unmeasured characteristics is significantly smaller $(-31 \%)$ for black workers in the private sector. This would seem counter intuitive if one views the private sector as being uniformly better able to accommodate differences in productivity but fits with high skill black workers sorting out of the private sector. As might be expected, the return for white workers is far larger-50\% larger-in the private sector than in the public sector, and the difference is statistically significant. Thus, blacks with unmeasured skills are more likely to be attracted to the public sector just as whites with unmeasured skills are more likely to be attracted to the private sector.

We briefly summarize the findings associated with our exploration of the public sector. First, black workers at the top of the skill distribution face less incentive to work in the private sector than do white workers. Second, and related, racial wage differentials in the public sector can be fully explained by observables, which we view as being consistent with the greater earnings rigidity induced by the more explicit rules determining compensation in the public sector. Third, unmeasured skills are rewarded to a far greater extent for white workers in the private sector. For blacks, this pattern is reversed with greater returns in the public sector.

We should be careful to reiterate that these findings may result from many forces. As a consequence, we refrain from making a strong causal link between, say, the fact that high skill black workers are paid the same in both sectors and high skill blacks being more likely to choose the public sector because they are discriminated against in the private sector. We simply do not have the evidence to substantiate such a strong conclusion. Yet, the various pieces of evidence we offer remain consistent with high skill black workers facing less "obvious" choices about sector and performance pay jobs than may be the case for high skill white workers.

\section{Conclusion}

In this paper we make several contributions. First, we demonstrate that the association of performance pay with increased inequality at the top end of the wage distribution in the United States is largely a whites only phenomenon. While black workers in performance pay are paid more than in non performance pay jobs over a fairly wide range of the distribution, the difference is more modest than in the case of white workers and it basically shrinks to zero at the top end at the same time as it increases sharply for whites. Second, because performance pay stretches the white earnings distribution but not the black distribution, the white-black earnings differential among those earning performance pay tends to grow over the earnings distribution, dramatically so in the top decile. This remains true even when examining suitable counterfactuals that hold constant observables between whites and blacks. Third, this pattern differs substantially from the white-black earnings differential

\footnotetext{
${ }^{21}$ Naturally, we should be cautious here and view this as a first-order approximation. If there are learning effects such as in Gibbons, Katz, Lemieux and Parent (2005), and those learning effects differ across sectors and races, then the underlying distributions of the worker components would be time-varying.
} 
among those not in performance pay jobs which tends to decline over the distribution and essentially reaches zero toward the top when examining the suitable counterfactuals. Finally, although our full analysis makes use of the PSID only, those broad patterns are consistent with what we observe for the younger cohort of workers followed in the NLSY.

Two broad hypotheses exist that might suggest why earnings differentials are larger at the top of the performance pay distribution. On the one hand, there may be unmeasured ability that if appropriately accounted for would cause the differentials to vanish when examining the counterfactuals. We note that including family background caused the racial earnings differential to decline but did not eliminate its run up at the very top of distribution which approached 30 percent. Nonetheless, the importance of the family background variables hints at the importance of unmeasured ability. Indeed, our unconditional quantile regression analysis showed clearly that educational attainment, labor market experience, and family background are key contributors to the white-black wage gap in performance pay jobs, supporting the importance of selection on skills in these types of jobs. On the other hand, the very large unexplained gap at the top of the distribution remains consistent with performance pay giving greater latitude for prejudice to be translated into earnings differentials. Finally, the possibility for selection between sectors causes these hypotheses to be related. If more able blacks felt they were not to be rewarded for their ability in performance pay jobs, they may not select those jobs even as more able whites do select them. Our evidence based on the AFQT as well as on the wage effect of being in a performance pay job is consistent with this differential pattern of selection.

\section{Appendix 1}

In this appendix we first outline the reweighting method developed in DiNardo, Fortin and Lemieux (1996) (henceforth DFL) used to compute counterfactual wage distributions. That method allows for comparing distributions across groups by fixing the composition of the observables to be the same in distribution. We then show how the procedure needs to be extended to handle the fact that we compare two groups of workers (blacks and whites) across two types of jobs (performance pay and non-performance pay), which introduces an added layer of conditioning.

\subsection{The Basic DFL Reweighting Procedure}

Consider the following two $(\log )$ wage $(w)$ distributions, one for blacks $(B=1)$ and one for whites $(B=0)$ :

$$
\begin{gathered}
g(w \mid B=1)=\int f(w \mid x, B=1) h(x \mid B=1) d x \\
g(w \mid B=0)=\int(w \mid x, B=0) h(x \mid B=0) d x
\end{gathered}
$$

where $g(), f()$ and $h()$ are densities. One may be interested in knowing what the distribution for whites would be if they had the same distribution of characteristics as that for blacks: 


$$
g_{B=1}^{c}(w \mid B=0)=\int f(w \mid x, B=0) h(x \mid B=1) d x
$$

From the definition of conditional probabilities we have:

$$
h(x)=\frac{h(x \mid B=1) \operatorname{Prob}(B=1)}{\operatorname{Prob}(B=1 \mid x)}
$$

and

$$
h(x)=\frac{h(x \mid B=0) \operatorname{Prob}(B=0)}{\operatorname{Prob}(B=0 \mid x)}
$$

Consequently,

$$
h(x \mid B=1)=\frac{h(x \mid B=0) \operatorname{Prob}(B=1 \mid x) \operatorname{Prob}(B=0)}{\operatorname{Prob}(B=0 \mid x) \operatorname{Prob}(B=1)}
$$

and one can rewrite the counterfactual distribution as

$$
g_{B=1}^{c}(w \mid B=0)=\int \Theta f(w \mid x, B=0) h(x \mid B=0) d x
$$

where $\Theta=\frac{\operatorname{Prob}(B=1 \mid x) \operatorname{Prob}(B=0)}{\operatorname{Prob}(B=0 \mid x) \operatorname{Prob}(B=1)}$. Thus we simply reweight the distribution for whites such that the underlying distribution of $x^{\prime} s$ matches that of blacks.

\subsection{Extension of DFL to Accommodate Multiple Dimensions of Choice}

In our application we are interested in the effect that being in a performance pay job $(p p j=1)$ has on the distribution of wages for both whites and blacks. We are also interested in computing counterfactual distributions such as what would happen to whites in performance pay jobs if they had the same distribution of $x^{\prime} s$ as blacks in performance pay jobs. This gives rise to an added complication in that non only do we compare whites and blacks, but we also want to make comparisons using both race and the type of compensation the workers have. One way to simplify this is simply to select the subsamples of interest and perform the standard DFL decomposition using two groups. For example, we may decide to keep workers in performance pay jobs only and then focus on white-black wage differences. Alternatively we can select blacks only and then look at differences across types of jobs. However performing such sample selections would result in estimating a different weight than the one we would obtain if we kept the full sample. To see this, suppose we want to know what the distribution of white wages $(B=0)$ in performance pay jobs $(p p j=1)$ would look like if they had the same distribution of $x^{\prime} s$ as blacks $(B=1)$ in performance pay jobs:

$$
g_{B=1, p p j=1}^{c}(w \mid B=0)=\int f(w \mid x, B=0, p p j=1) h(x \mid B=1, p p j=1) d x
$$

Again using the definition of conditional probabilities we have: 


$$
h(x)=\frac{h(x \mid B=1, p p j=1) \operatorname{Prob}(p p j=1 \mid B=1) \operatorname{Prob}(B=1)}{\operatorname{Prob}(B=1 \mid x) \operatorname{Prob}(p p j=1 \mid x, B=1)}
$$

and

$$
h(x)=\frac{h(x \mid B=0, p p j=1) \operatorname{Prob}(p p j=1 \mid B=0) \operatorname{Prob}(B=0)}{\operatorname{Prob}(B=0 \mid x) \operatorname{Prob}(p p j=1 \mid x, B=0)}
$$

Hence

$$
\begin{aligned}
h(x \mid B=1, p p j=1)= & \frac{h(x \mid B=0, p p j=1) \operatorname{Prob}(B=0 \mid x) \operatorname{Prob}(p p j=1 \mid x, B=1)}{\operatorname{Prob}(B=0 \mid x) \operatorname{Prob}(p p j=1 \mid x, B=0)} \\
& \times \frac{\operatorname{Prob}(p p j=1 \mid B=0) \operatorname{Prob}(B=0)}{\operatorname{Prob}(p p j=1 \mid B=1) \operatorname{Prob}(B=1)}
\end{aligned}
$$

As in the standard DFL weight, the last part can be dropped as those probabilities simply represent sample proportions. Thus the counterfactual wage distribution is equal to:

$$
g_{B=1, p p j=1}^{c}(w \mid B=0)=\int \Theta f(w \mid x, B=0, p p j=1) h(x \mid B=0, p p j=1) d x
$$

where $\Theta=\frac{\operatorname{Prob}(B=1 \mid x) \operatorname{Prob}(p p j=1 \mid x, B=1)}{\operatorname{Prob}(B=0 \mid x) \operatorname{Prob}(p p j=1 \mid x, B=0)}$. The weight computed using the pre-selected subsample of workers in performance pay jobs, $\frac{\operatorname{Prob}(B=1 \mid x)}{\operatorname{Prob}(B=0 \mid x)}$ would be equal to $\Theta$ only if $\frac{\operatorname{Prob}(p p j=1 \mid x, B=1)}{\operatorname{Prob}(p p j=1 \mid x, B=0)}=1$. There is little reason to suspect that this need be true in general as it requires that the selection process into performance pay jobs be exactly the same for whites and blacks. We use this extended DFL decomposition to compute the various counterfactual distributions of interest.

\section{Appendix 2: How Misclassification Affects the White-Black Wage Gap in the NLSY}

In this appendix we show under a certain set of conditions that the mean wage gap between white workers and black workers in non performance pay jobs tends to be magnified due to the fact that some performance pay jobs are wrongly classified as non performance pay jobs. Let $P P J^{*}$ be a dummy indicating whether a job is truly one that pays for performance. The probability that $P P J^{*}=1$ depends on observed characteristics $X$ (education, occupation, etc.) and race:

$$
\operatorname{Pr}\left(P P J^{*}=1 \mid X, j\right)=q(X, j) . \quad j=\text { White }, \text { Black }
$$

Let $P$ represent the probability that we observe a performance payment in a given time period, conditional on $P P J^{*}=1$, and let $T$ represent the number of observations we have for a job match. It follows that:

$$
\operatorname{Pr}(P P J=1 \mid X, T, j)=q(X, T, j)=q(X, j)\left[1-(1-P)^{T}\right]
$$


and

$$
\operatorname{Pr}\left(P P J^{*}=1 \mid P P J=1, X, T, j\right)=\operatorname{Pr}\left(P P J^{*}=1 \mid P P J=1, j\right)=1
$$

where $P P J=1$ if we observe a performance payment for the job at least once. So if we observe $P P J=1$, we make the assumption that we know for sure that it is really a performance-pay job $\left(P P J^{*}=1\right)$. But when we observe $P P J=0$, it may be that the job is or is not one that pays for performance. We have:

$$
\begin{aligned}
\operatorname{Pr}\left(P P J^{*}\right. & =1 \mid P P J=0, X, T, j)=\frac{\operatorname{Pr}\left(P P J^{*}=1, P P J=0 \mid X, T, j\right)}{\operatorname{Pr}(P P J=0 \mid X, T, j)} \\
& =\frac{q(X, j)-q(X, T, j)}{1-q(X, T, j)}
\end{aligned}
$$

which is the fraction of PPJ misclassified as non-PPJ, and

$$
\operatorname{Pr}\left(P P J^{*}=0 \mid P P J=0, X, T\right)=\frac{1-q(X, j)}{1-q(X, T, j)}
$$

Using the wage equations

$$
\begin{aligned}
W_{j}^{p} & =X_{j} b_{j}^{p}+e_{j}^{p}, \\
W_{j}^{n} & =X_{j} b_{j}^{n}+e_{j}^{n},
\end{aligned}
$$

where the superscripts $p$ and $n$ represent performance pay and non performance pay jobs respectively, and the assumption that $P P J^{*}$ does not depend on the error term (it only depends on $X$ as well as the race indicator), it follows that:

$$
\begin{aligned}
E(W \mid P P J & =0, X, T, j)=\operatorname{Pr}\left(P P J^{*}=1 \mid P P J=0, X, T, j\right) \cdot E\left(W \mid P P J^{*}=1, X, j\right) \\
+\operatorname{Pr}\left(P P J^{*}\right. & =0 \mid P P J=0, X, T, j) \cdot E\left(W \mid P P J^{*}=1, X, j\right) \\
& =\frac{q(X, j)-q(X, T, j)}{1-q(X, T, j)} \cdot X_{j} b_{j}^{p}+\frac{1-q(X, j)}{1-q(X, T, j)} \cdot X_{j} b_{j}^{n} \\
& =X_{j} b_{j}^{p}+\frac{1-q(X, j)}{1-q(X, T, j)} \cdot X_{j}\left(b_{j}^{n}-b_{j}^{p}\right)
\end{aligned}
$$

Our interest is in estimating ${ }^{22}$

$$
\begin{aligned}
E(W \mid P P J= & 0, X, T, \text { White })-E(W \mid P P J=0, X, T, \text { Black }) \\
= & \left(X_{W} b_{W}^{p}-X_{B} b_{B}^{p}\right)+\frac{1-q(X, \text { White })}{1-q(X, T, \text { White })} \cdot X_{W}\left(b_{W}^{n}-b_{W}^{p}\right) \\
& -\frac{1-q(X, \text { Black })}{1-q(X, T, \text { Black })} \cdot X_{B}\left(b_{B}^{n}-b_{B}^{p}\right)
\end{aligned}
$$

\footnotetext{
${ }^{22}$ Given our assumption that the observed performance pay jobs status is a fully reliable signal of true status, the white-black wage gap in performance pay jobs is not affected by misclassification errors.
} 
Note that if there were no misclassification errors then the probability ratios would be equal to one and we would have:

$$
E(W \mid P P J=0, X, T, \text { White })-E(W \mid P P J=0, X, T, B l a c k)=\left(X_{W} b_{W}^{n}-X_{B} b_{B}^{n}\right)
$$

In terms of estimation, $q(X, T, j)$ can be estimated by fitting a logit or linear probability model (with year dummies being part of $X$ ) for each group. Now, from the equation

$$
\operatorname{Pr}(P P J=1 \mid X, T, j)=q(X, T, j)=q(X, j)\left[1-(1-P)^{T}\right]
$$

it follows that $q(X, j)=\lim _{T \rightarrow \infty} q(X, T, j)$.

With any reasonable value of $P$ (e.g. $P=.25$, i.e. performance pay received only one year out of four), it follows that when $T$ is large we have $q(X,, j) \approx q(X, j)$. However, one problem with using the NLSY is that tenure levels are low, which prevents us from relying on that approximation when using that data set. With the PSID, though, the longest $T$ observed in the data is 22 . So to circumvent the issue of the short NLSY panel we can run a logit model using the PSID to estimate $q(X, T, j)$ as the predicted probability of performance pay, and get $q(X, j)$ by replacing the observed value of $T$ with $T=22$ (this gives us an estimate of $\frac{1-q(X, j)}{1-q(X, T, j)}$ for $j=$ Blacks, Whites in the PSID). Then we use the NLSY to estimate get an estimate of $q(X, T, j)$ specific to that data set. To get an estimate of $\frac{1-q(X, j)}{1-q(X, T, j)}$ for workers in the NLSY we then use the approximation of $q(X, j)$ computed with the PSID divided by the estimate of $q(X, T, j)$ obtained using the NLSY. Those estimates are:

\begin{tabular}{|c|c|c|}
\hline & Blacks & Whites \\
\hline \hline $1-q(X, j)-$ PSID & .438 & .371 \\
\hline $1-q(X, T, j)-$ PSID & .658 & .583 \\
\hline $1-q(X, T, j)-$ NLSY & .777 & .705 \\
\hline$\frac{1-q(X, j)}{1-q(X, T, j)}-$ PSID & .666 & .636 \\
\hline$\frac{1-q(X, j)}{1-q(X, T, j)}-\mathrm{NLSY}$ & .564 & .526 \\
\hline
\end{tabular}

Not surprisingly given the shorter NLSY panel, the probability that a performance pay job is wrongly classified as a non performance pay job is higher. If we re-write equation (4) using as a further approximation the fact that $r(W) \equiv \frac{1-q(X, \text { White })}{1-q(X, T, \text { White })} \approx \frac{1-q(X, \text { Black })}{1-q(X, T, \text { Black })} \equiv r(B)$, after some re-arrangement we get:

$$
\begin{aligned}
E(W \mid P P J= & 0, X, T, \text { White })-E(W \mid P P J=0, X, T, \text { Black }) \\
& =(1-r(B))\left(X_{W} b_{W}^{p}-X_{B} b_{B}^{p}\right)+r(B)\left(X_{W} b_{W}^{n}-X_{B} b_{B}^{n}\right)
\end{aligned}
$$

Thus, the measured average White-Black wage gap in non performance pay jobs turns out to be a linear combination of the true wage gap $\left(X_{W} b_{W}^{n}-X_{B} b_{B}^{n}\right)$ and the performance pay job wage gap 
$\left(X_{W} b_{W}^{p}-X_{B} b_{B}^{p}\right)$. We can see that the lower is the ratio $r(B)$ the greater will be the weight placed on the gap between white and black workers in performance pay jobs. Consequently, we would expect that the raw non performance pay job wage gap measured in the NLSY would be larger than in the PSID, all else held equal. Note that the derivation above is for the mean wage gap. Looking at Appendix Figure 2, we can see that the gap in performance pay jobs increases sharply once we reach the top decile of the distribution. Assuming a constant true wage gap in non performance pay jobs, we would nevertheless see an increase in the measured gap due to the increasing importance of the first term on the right-hand side of equation (5).

The main caveat to this analysis is that we are assuming that non performance pay jobs are never misclassified as performance pay jobs. Whether e.g. a Christmas bonus makes a job a performance pay job is debatable. We also assume that the adjustment ratios for Blacks and Whites are the same. The estimates shown above suggest that this may be a reasonable approximation. 


\section{References}

Baker, George, "Incentive Contracts and Performance Measurement," Journal of Political Economy, June 1992, 100, 598-614.

Banker, Rajiv, Seok-Young Lee, and Dhinu Srinivasan, "An Empirical Analysis of Continuing Improvements Following the Implementation of a Performance-Based Compensation Plan," Journal of Accounting and Economics, 2000, 30, 315-350.

Barsky, Robert, John Bound, Kerwin Charles, and Joseph Lupton, "Accounting for the Black-White Wealth Gap: A Nonparametric Approach," Journal of the American Statistical Association, 2002, 97 (459), 663-673.

Barth, Erling, Bernt Bratsberg, Tobjorn Haegeland, and Oddbjorn Raaum, "Performance Pay and Within-Firm Wage Inequality," 2009. Discussion Paper No.4137, IZA, Bonn Germany.

Bender, Keith, "Examining Equality between Public and Private Sector Wage Distributions," Economic Inquiry, 2003, 41 (1), 62-79.

Berzebat, Debra and James W. Hughes, "Sex Discrimination in the Labor Market: The Role of Statistical Evidence: Comment," American Economic Review, 1990, 80 (1), 277-286.

Black, Dan A., Amelia Haviland, Seth Sanders, and Lowell Taylor, "Why Do Minority Men Earn Less? A Study of Wage Differentials among the Highly Educated," Review of Economics and Statistics, 2006, 88 (2), 283-299.

Borjas, George J., "The Wage Structure and the Sorting of Workers into the Public Sector," 2002. NBER Working Paper No. W9313, Cambridge MA.

Boudarbat, Brahim and Thomas Lemieux, "Why Are the Relative Wages of Immigrants Declining? A Distributional Approach," April 2007. University of British Columbia, Department of Economics working paper.

Bound, John and Richard Freeman, "What Went Wrong? The Erosion of the Relative Earnings and Employment among Young Black Men in the 1980s," Quarterly Journal of Economics, 1992, 107 (1), 151-200.

Bronars, Stephen G. and Carl Moore, "Incentive Pay, Information, and Earnings: Evidence from the NLSY," 1995. Discussion Paper, Report: NLS95-23, US Department of Labor, Bureau of Labor Statistics.

Brown, Charles, "Black-White Earnings Ratios Since the Civil Rights Act of 1964: the Importance of Labor Market Dropouts," Quarterly Journal of Economics, 1984, 99 (1), 31-44.

Brown, Michelle and John S. Heywood, "Performance Appraisal Systems: Determinants and Change," British Journal of Industrial Relations, 2005, 43 (4), 659-679. 
Card, David and Thomas Lemieux, "Changing Wage Structure and Black-White Wage Differentials," American Economic Review, 1994, 84 (2), 29-33.

_ and _, "Wage Dispersion, Returns to Skill, and Black-White Wage Differentials," Journal of Econometrics, 1995, 74 (2), 319-361.

Castilla, Emilio J., "Gender, Race and Meritocracy in Organizational Careers," American Journal of Sociology, 2008, 113 (6), 1479-26.

Chay, Kenneth and David Lee, "Change in Relative Wages in the 1980s: Returns to Observed and Unobserved Skills and Black-White Wage Differentials," Journal of Econometrics, 2000, 78 (1) $1-38$.

Couch, Kenneth and Mary Daly, "Black-White Wage Inequality in the 1990s: A Decade in Progress," Economic Inquiry, 2002, 40 (1), 31-41.

Curme, Michael and Noah Stefanec, "Worker Quality and Labor Market Sorting," Economics Letters, 2007, 96, 202-208.

DiNardo, John, Nicole Fortin, and Thomas Lemieux, "Labor Market Institutions and the Distribution of Wages, 1973-1992: A Semiparametric Approach," Econometrica, September 1996, 64 (5), 1001-1044.

Dohmen, Thomas and Armin Falk, "Performance Pay and Multi-dimensional Sorting: Productivity, Preference and Gender," 2001. Discussion Paper 2001, IZA.

Fang, Tony and John S. Heywood, "Output Pay and Ethnic Wage Differentials: Canadian Evidence," Industrial Relations, 2006, 45 (2), 173-194.

Firpo, Sergio, Nicole Fortin, and Thomas Lemieux, "Unconditional Quantile Regressions," Econometrica, May 2009, 77 (3), 953-973.

Gibbons, Robert, Lawrence Katz, Thomas Lemieux, and Daniel Parent, "Comparative Advantage, Learning, and Sectoral Wage Determination," Journal of Labor Economics, 2005, 23 (4), 681-724.

Heywood, John and P. O'Halloran, "Racial Earnings Differentials and Performance Pay," Journal of Human Resources, 2005, 40 (2), 435-453.

Heywood, John S., "Wage Discrimination by Race and Gender in the Public and Private Sectors," Economics Letters, 1989, 29(1), 99-102.

- and Patrick O'Halloran, "Market Structure, Payment Methods, and Racial Earnings Differentials," in John S. Heywood and James H. Peoples, eds., Product Market Structures and Racial Earnings Differentials, State University of New York Press: Albany, 2006, pp. 187-208. 
- and Uwe Jirjahn, "Payment Schemes and Gender in Germany," Industrial and Labor relations Review, 2002, 56 (1), 68-84.

Holzer, Harry and Keith R. Ihlanfeldt, "Customer Discrimination and Employment Outcomes for Minority Workers," Quarterly Journal of Economics, 1998, 113 (3), 835-867.

Jirjahn, Uwe and Gesine Stephan, "Gender, Piece Rates, and Wages: Evidence from Matched Employer-Employee Data," Cambridge Journal of Economics, 2004, 28 (5), 683-704.

Johnson, William R. and Derek A. Neal, "The Role of Premarket Factors in Black-White Wage Differences," Journal of Political Economy, 1996, 104 (5), 869-895.

_ and _ , "Basic Skills and the Black-White Earnings Gap," in Christopher Jencks and Meredith Phillips, eds., The Black-White Score Gap, Brookings Institution, Washington DC, 1998.

Juhn, Chinhui, Kevin M. Murphy, and Brooks Pierce, "Accounting for the Slowdown in Black-White Wage Convergence," in M.H. Kosters, ed., Workers and Their Wages: Changing Patterns in the United States, AEI Press: Washington, DC, 1991.

_ , _, and _ ,Wage Inequality and the Rise in Returns to Skill," Journal of Political Economy, $1993,101(3), 410-442$.

Kahn, Lawrence M., "Customer Discrimination and Affirmative Action," Economic Inquiry, 1991, $29(3), 555-571$.

Lang, Kevin, Poverty and Discrimination, Princeton, New Jersey: Princeton University Press, 2007.

Lazear, Edward P., "Performance Pay and Productivity," American Economic Review, December $2000,90(5), 1346-1361$.

Lemieux, Thomas, W. Bentley MacLeod, and Daniel Parent, "Performance Pay and Wage Inequality," Quarterly Journal of Economics, 2009, 124 (1), 1-49.

MacDonald, Glenn and Leslie M. Marx, "Adverse Specialization," Journal of Political Economy, 2001, 109 (4), 864-899.

MacLeod, W. Bentley, "Optimal Contracting with Subjective Evaluation," American Economic Review, 2003, 93 (1), 216-240.

Madden, Janice Fanning, "Performance Pay and Gender Discrimination: Commissions for Stockbrokers," 2008. Working Paper, Population Studies Center, University of Pennsylvania.

Marta, Elvira and Robert Town, "The Effects of Race and Worker Productivity on Performance Evaluations," Industrial Relations, 2001, 40 (4), 571-590. 
Milkovich, George T. and Alexandra K. Wigdor, "Introduction," in George T. Milkovich and Alexandra K. Wigdor, eds., Pay for Performance: Evaluating Performance Appraisal and Merit Pay, National Academy Press, Washington, D.C., 1991.

Neal, Derek A., "The Measured Black-White Wage Gap Among Women is Too Small," Journal of Political Economy, 2004, 112 (3), s1-s28.

Reardon, Elaine, "Demand Side Changes and the Relative Economic Progress of Black Men: 1940-1990," Journal of Human Resources, 1997, 32 (1), 69-97.

Rogers, William M., "Male White-Black Wage Gaps, 1979-1994: A Distributional Analysis," Southern Economic Journal, 2006, 72 (4), 773-793.

Smith, D. Alton, "Government Employment and Black/White Relative Wages," Journal of Human Resources, 1980, $12(1), 77-86$.

Sorensen, Rune and Jostein Grytten, "Practice Variation and Physician-Specific Effects," Journal of Health Economics, 2003, 22 (3), 403-418.

Weinberger, Catherine, "Race and Gender Wage Gaps in the Market for Recent College Graduates," Industrial Relations, 1998, 37, 67-84.

- and Lois Joy, "Relative Earnings of Black College Graduates, 1980-2001," in Marlene Kim, ed., Race and Economic Opportunity in the Twenty-First Century, Routledge: New York, 2007. 
Figure 1. White-Black Log Wage Gap at each Percentile: 1976-1999 March CPS Smoothed by Locally Weighted Regression
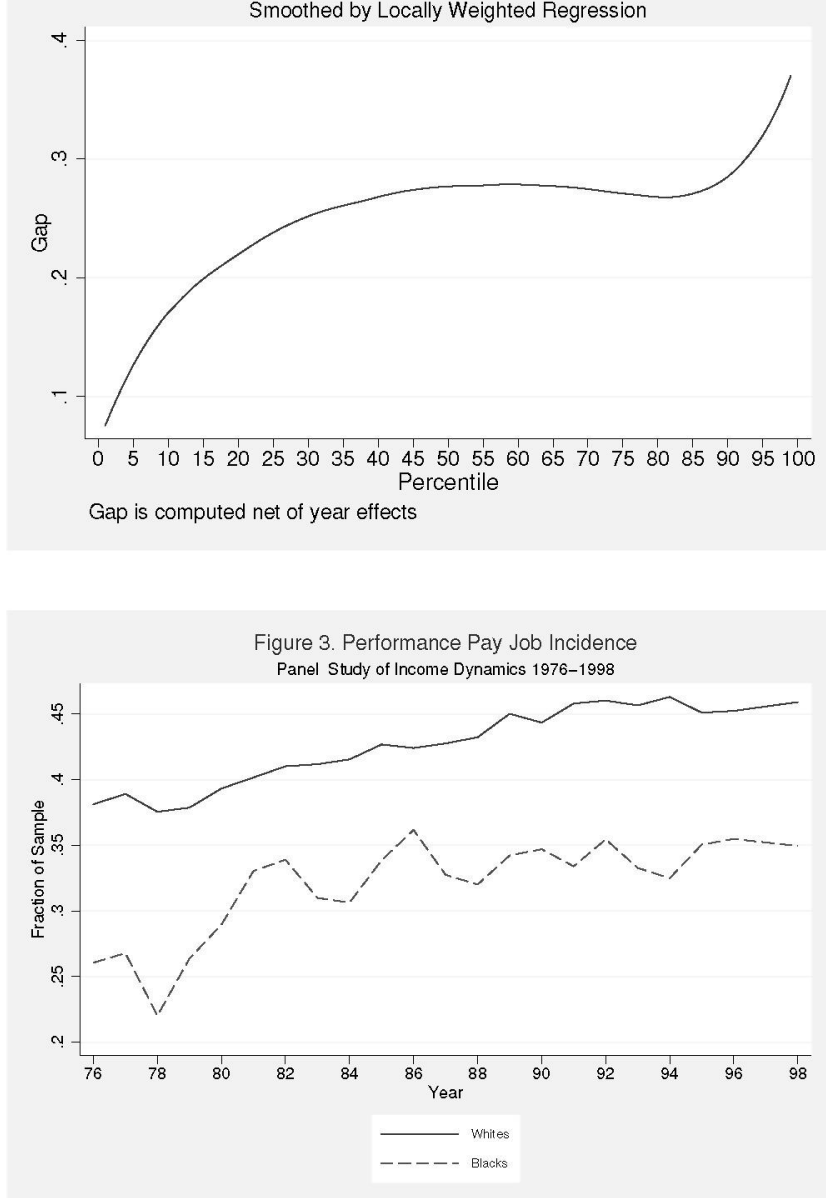

Figure 5. Distribution of Log Wages in Performance Pay Jobs PSID: 1976-1998

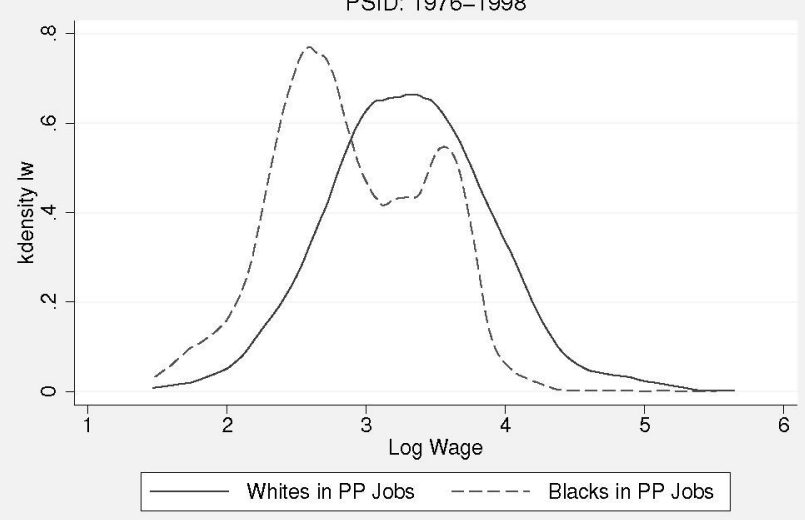

Figure 2. White-Black Log Wage Gap at each Percentile: 1976-1999 PSID Smoothed by Locally Weighted Regression

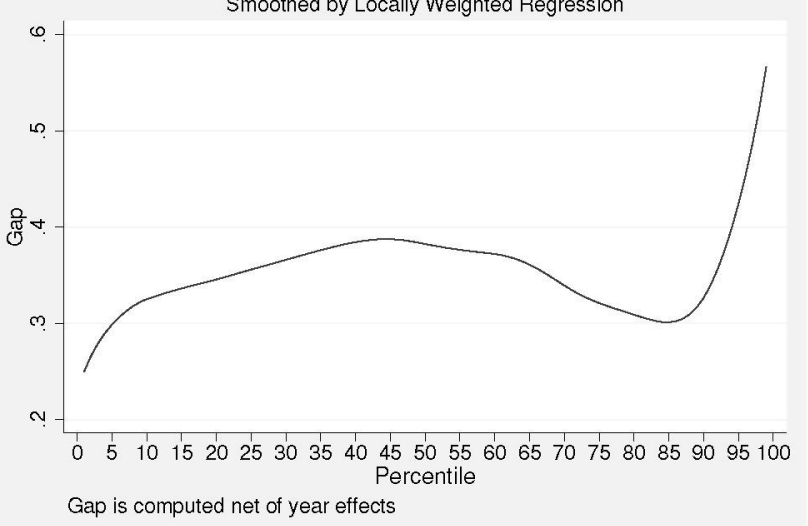

Figure 4. Incidence by Percentile of Wage Distribution PSID: 1976-1998
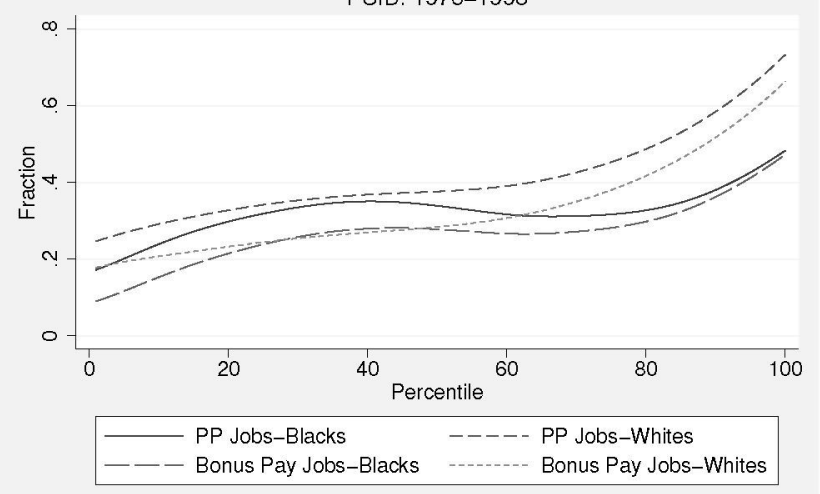
Smoothed by Locally Weighted Regression

Figure 6. Distribution of Log Wages in Non-Performance Pay Jobs PSID: 1976-1998

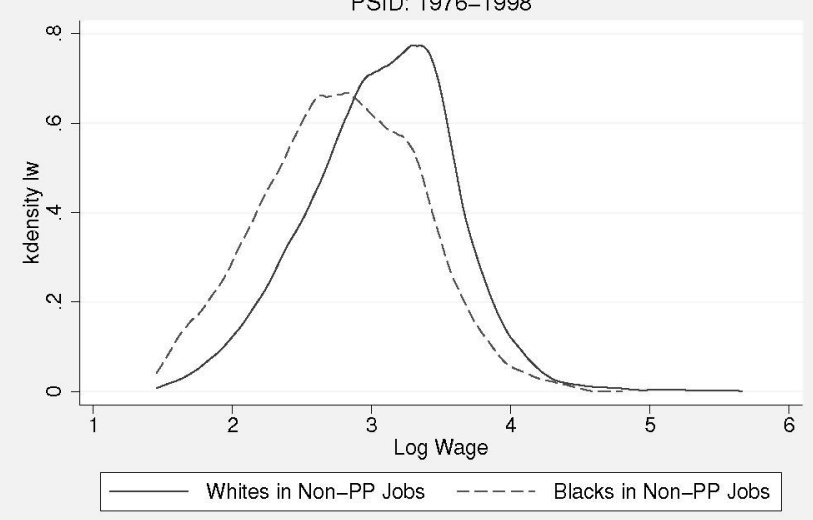



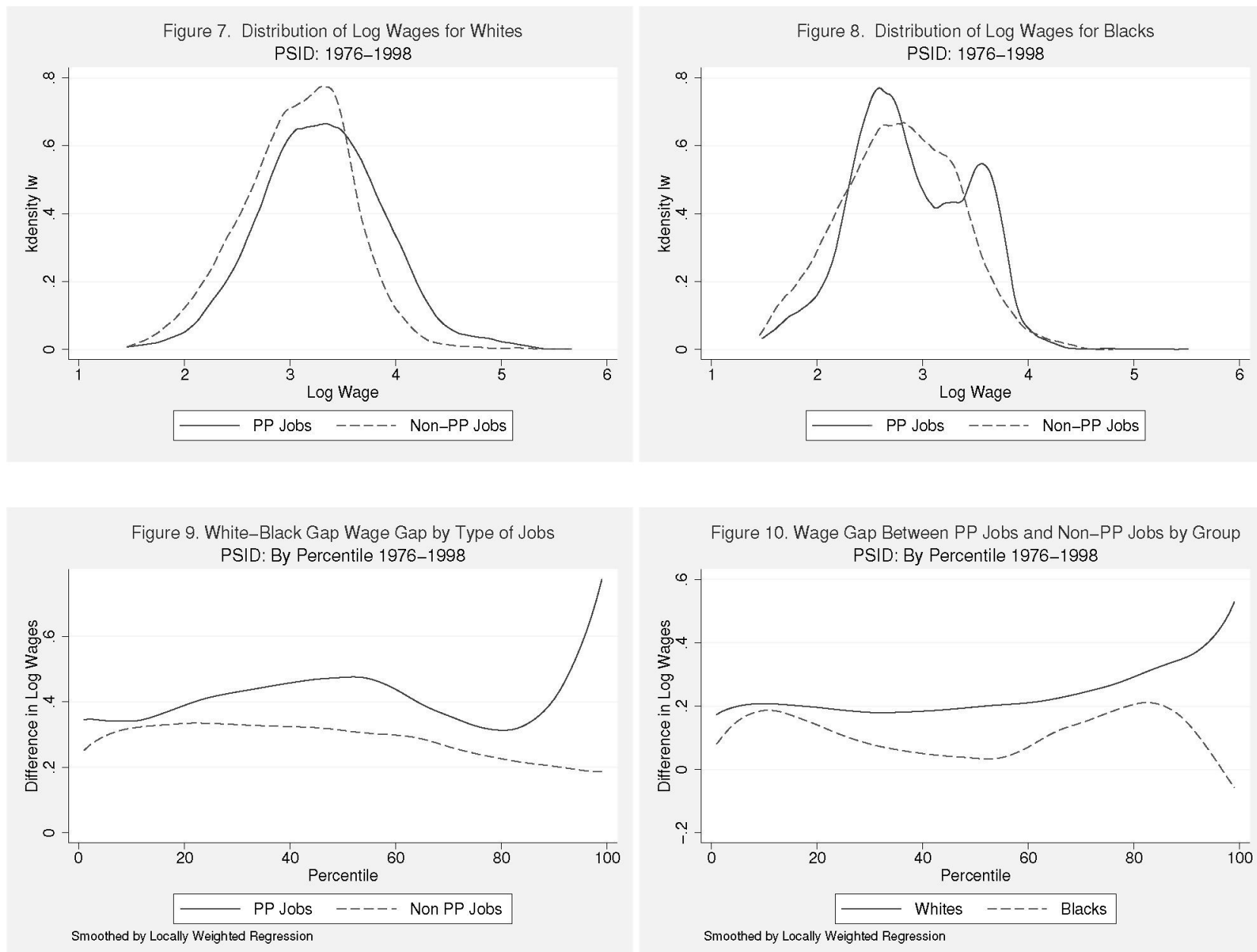

Figure 10. Wage Gap Between PP Jobs and Non-PP Jobs by Group

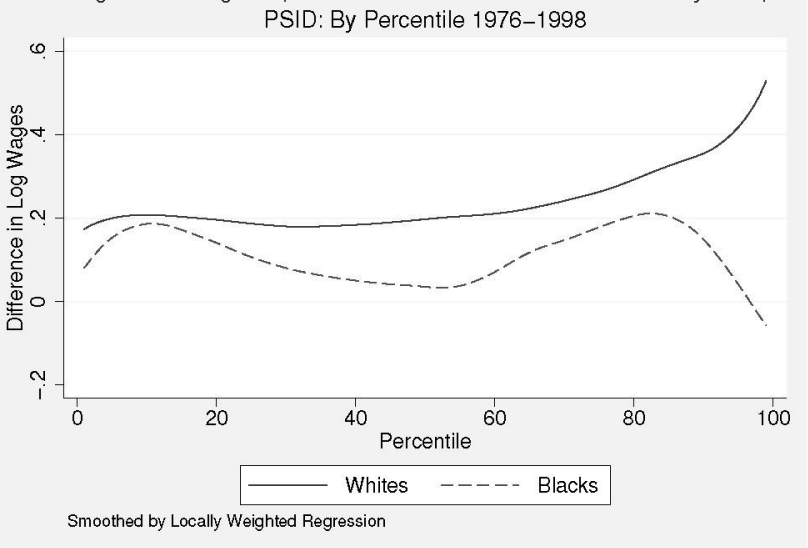

Figure 11. Black-White Wage Gap in Performance Pay Jobs PSID: 1976-1998

Figure 12. Black-White Wage Gap in Non Performance Pay Jobs PSID: 1976-1998
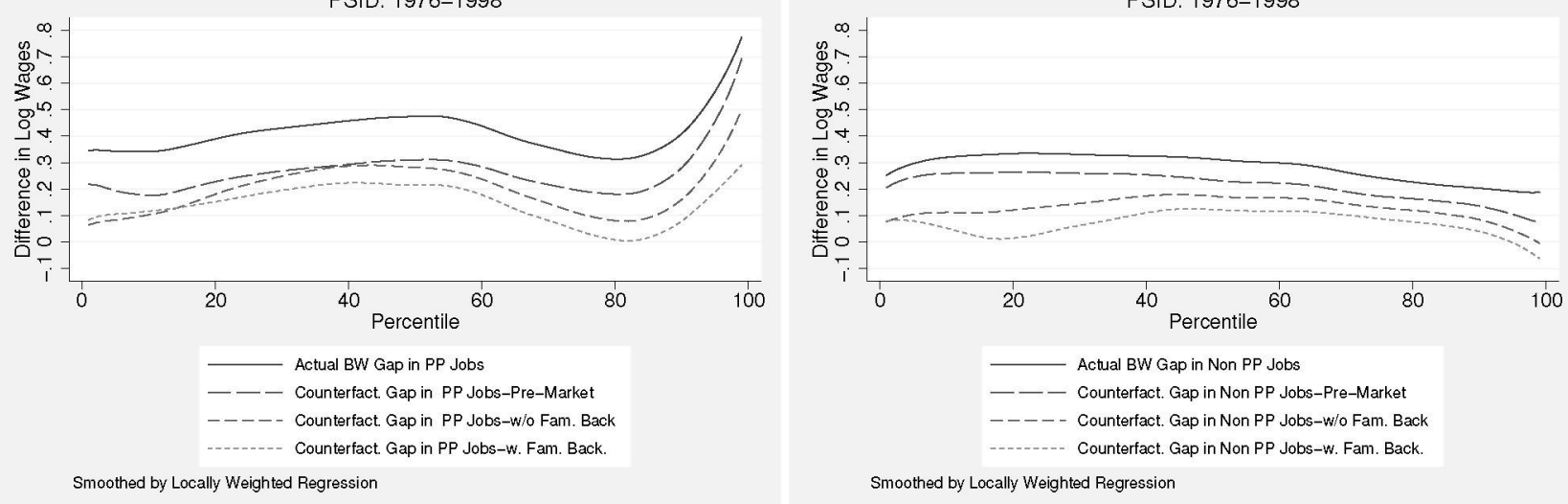

Smoothed by Locally Weighted Regression 

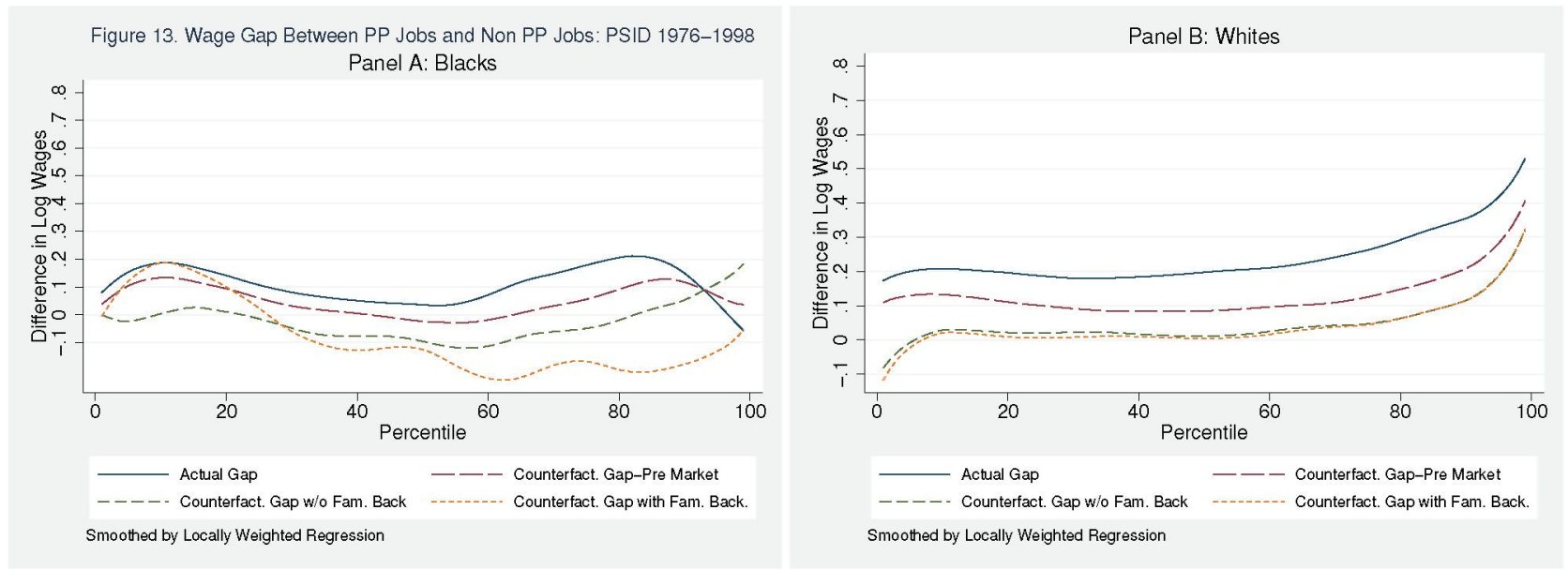

Figure 14. Decomposition of Wage Gaps: PSID 1976-1998 95\% Confidence Intervals

PP Jobs W/O Fam. Back.

PP Jobs With Fam Back.
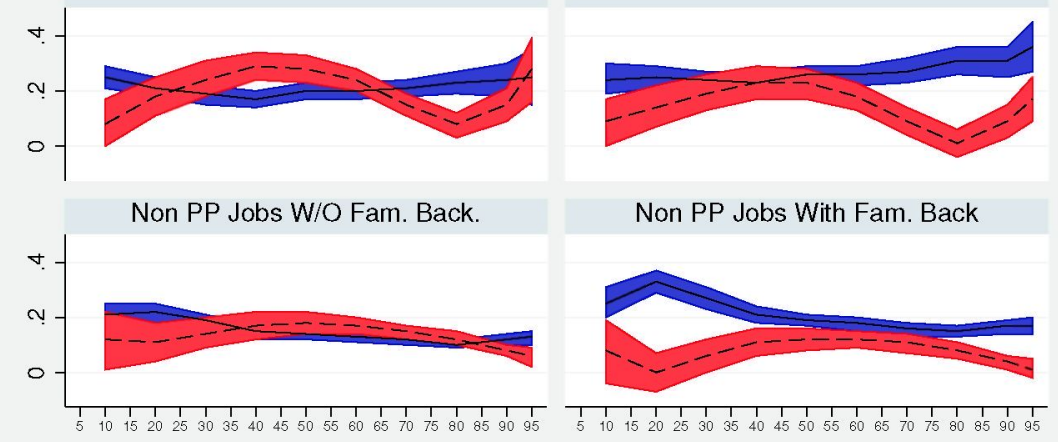

Quantile

High/Low High/Low

Composition Effect - - - - Wage Structure Effect

Graphs by PP Job Status 

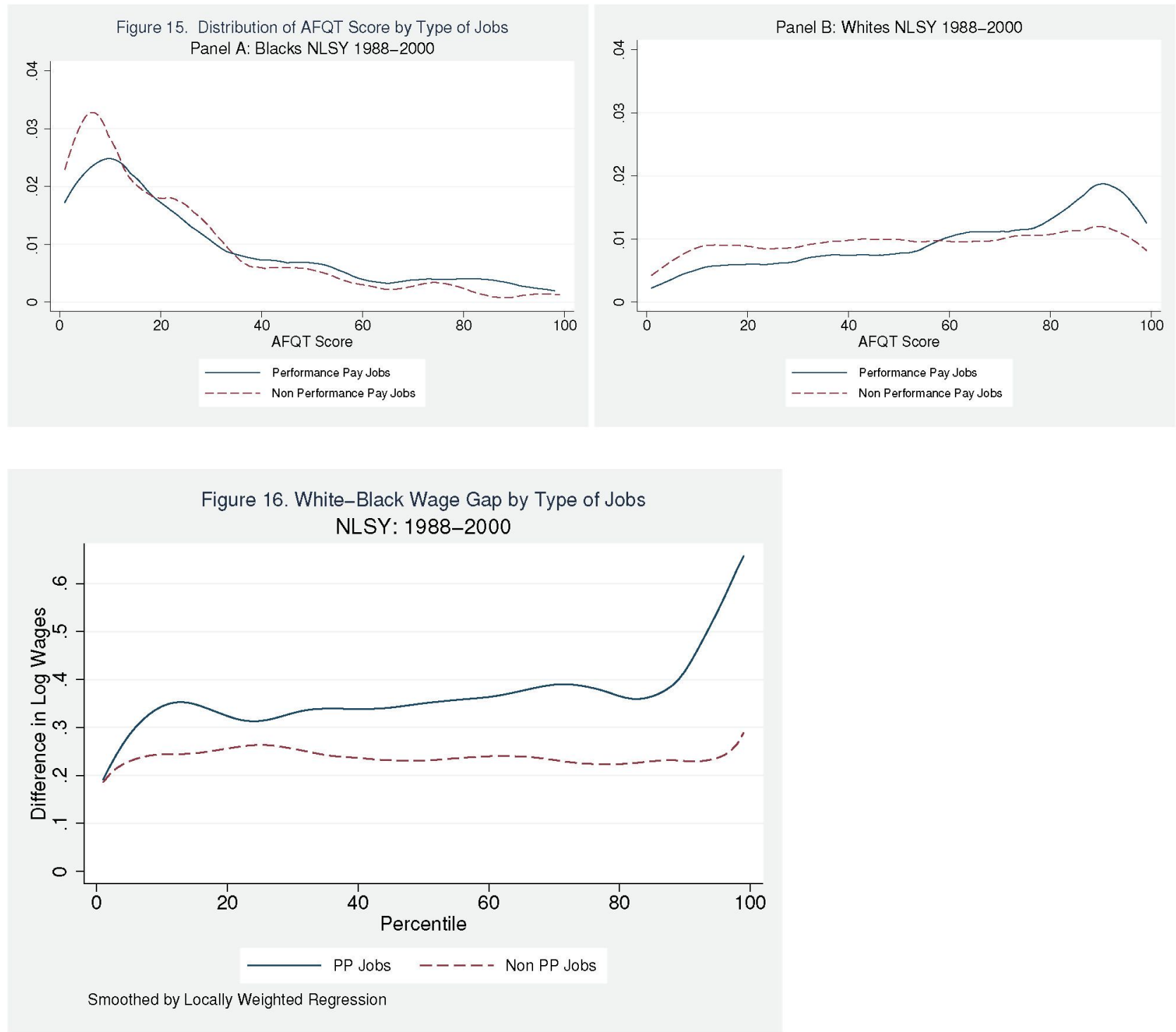
Figure 17. Wage Gap Between Private and Public Sectors: PSID 1976-1998

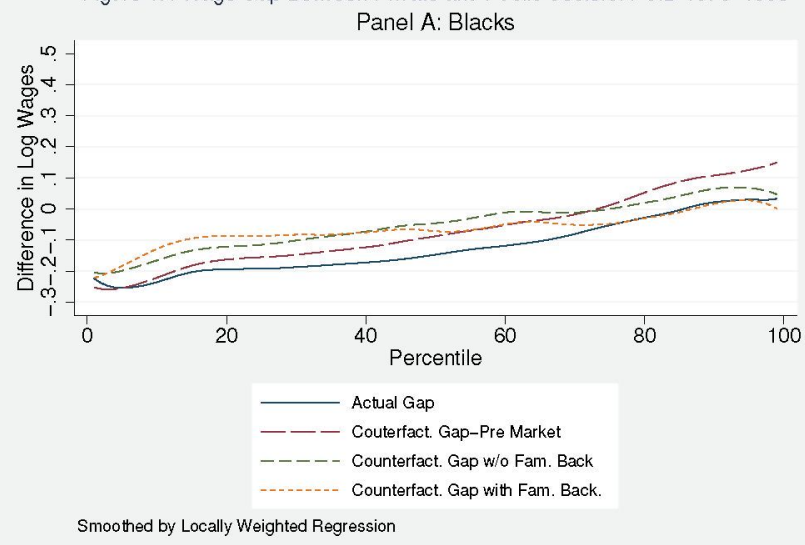

Panel B: Whites

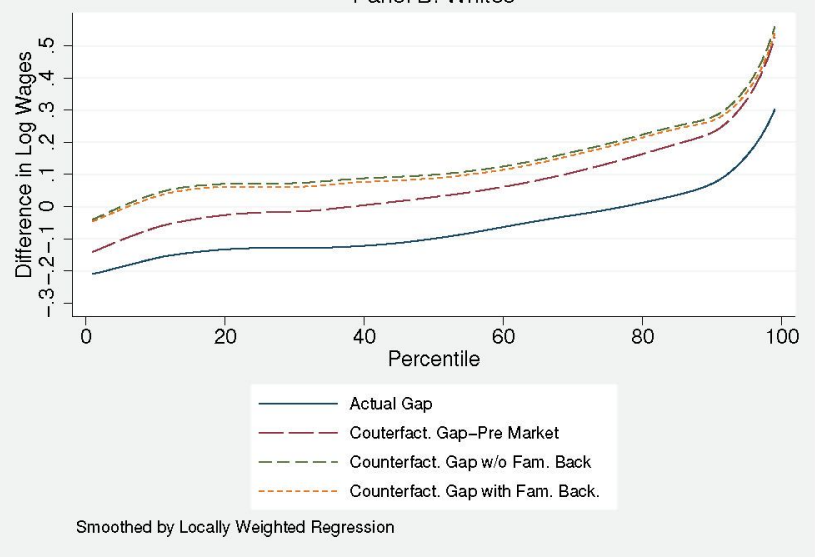

Figure 18. White-Black Wage Gap in Public Sector Jobs PSID: 1976-1998

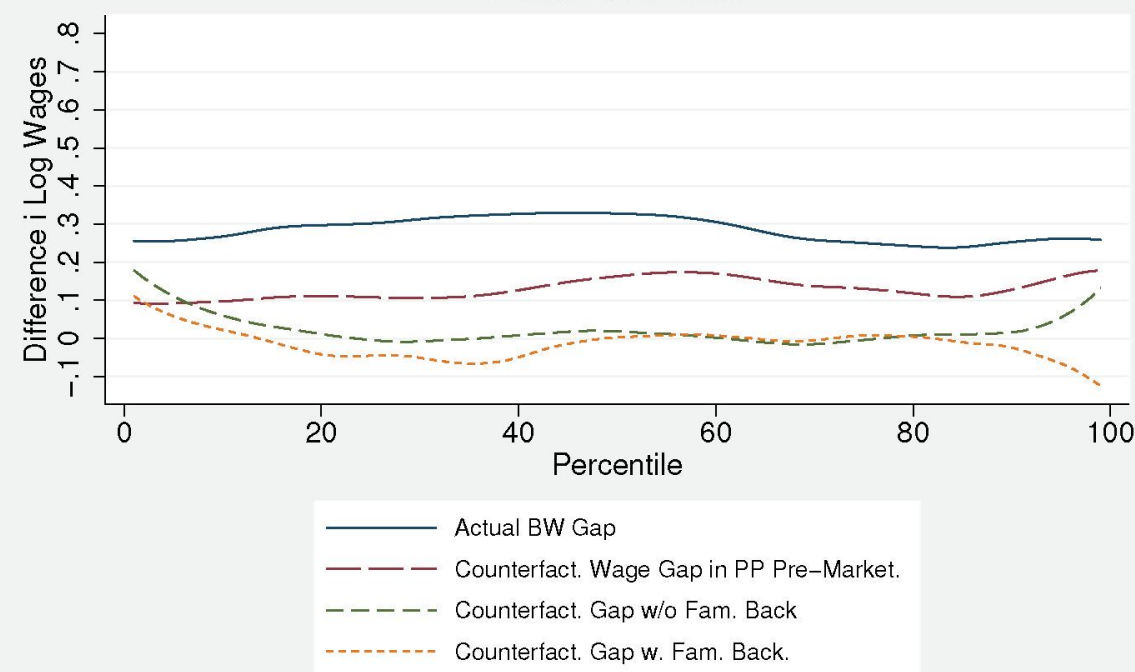

Smoothed by Locally Weighted Regression 


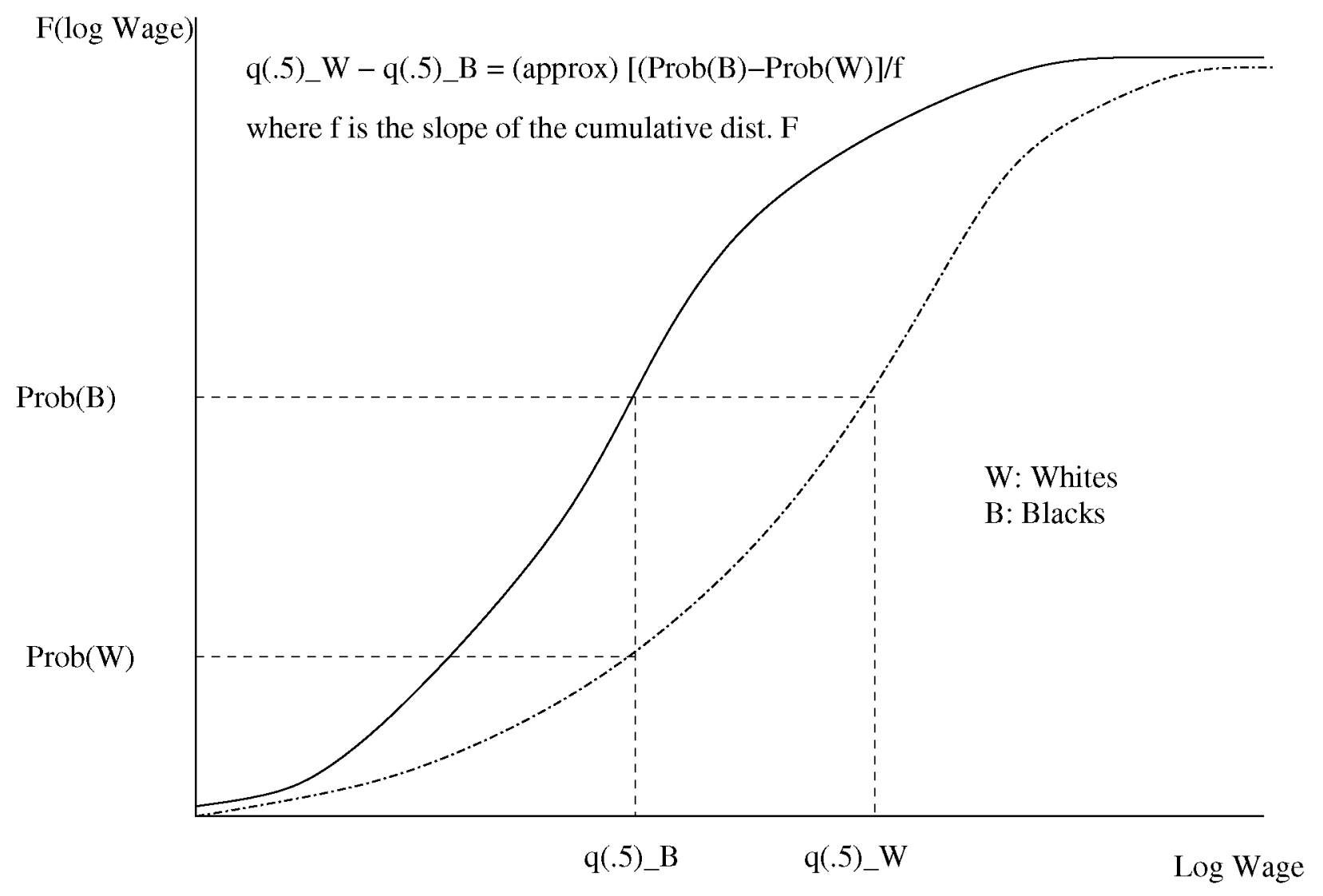

Figure A1. The RIF Method 
Table 1. Summary Statistics: Panel Study of Income Dynamics 1976-1998

\begin{tabular}{|c|c|c|c|c|}
\hline & \multicolumn{2}{|c|}{ Blacks } & \multicolumn{2}{|c|}{ Whites } \\
\hline & $\begin{array}{c}\text { Non-performance- } \\
\text { pay Jobs } \\
{[1]}\end{array}$ & $\begin{array}{c}\text { Performance-pay } \\
\text { Jobs } \\
\text { [2] }\end{array}$ & $\begin{array}{c}\text { Non-performance- } \\
\text { pay Jobs } \\
{[1]}\end{array}$ & $\begin{array}{c}\text { Performance-pay } \\
\text { Jobs } \\
{[2]}\end{array}$ \\
\hline Average Hourly Earnings ( $\$ 2008$ ) & 18.80 & 21.03 & 24.73 & 32.45 \\
\hline Age & 38.11 & 37.75 & 38.16 & 39.17 \\
\hline Education & 11.78 & 12.39 & 12.60 & 13.49 \\
\hline Potential Experience & 20.34 & 19.36 & 19.56 & 19.68 \\
\hline Employer Tenure & 6.47 & 10.99 & 7.58 & 9.15 \\
\hline Married & 0.60 & 0.60 & 0.73 & 0.79 \\
\hline Covered by CBA & 0.32 & 0.30 & 0.27 & 0.13 \\
\hline Paid by the Hour & 0.82 & 0.57 & 0.64 & 0.28 \\
\hline Paid a Salary & 0.16 & 0.29 & 0.34 & 0.53 \\
\hline Annual Hours Worked & 2018.07 & 2221.61 & 2137.04 & 2296.18 \\
\hline Father high school graduate & 0.20 & 0.30 & 0.24 & 0.28 \\
\hline Mother high school graduate & 0.20 & 0.38 & 0.42 & 0.43 \\
\hline Father B.A.+ & 0.02 & 0.03 & 0.09 & 0.12 \\
\hline Mother B.A.+ & 0.02 & 0.01 & 0.05 & 0.09 \\
\hline Father professional & 0.01 & 0.04 & 0.08 & 0.11 \\
\hline Father manager & 0.01 & 0.01 & 0.05 & 0.07 \\
\hline \# workers (Tot:2908) & 797 & 302 & 1702 & 923 \\
\hline \# Job Matches (Tot: 7159) & 1683 & 383 & 3747 & 1346 \\
\hline \# Observations (Tot: 25258) & 4771 & 2157 & 11059 & 7271 \\
\hline $\begin{array}{l}\text { Notes: The sample consists of mal } \\
\text { sector, wage and salary jobs. All fi } \\
\text { Education, potential experience, a } \\
\text { Potential experience is defined as } \\
\text { jobs are employment relationships } \\
\text { includes a variable pay componen } \\
\text { who reports overtime pay is consi } \\
\text { are considered unionized if they a } \\
\text { If the respondents either do not kr } \\
\text { do not want to answer, then those }\end{array}$ & $\begin{array}{l}\text { household heads age } \\
\text { res in the table repre } \\
\text { l employer tenure ar } \\
\text { je minus education } \mathrm{m} \\
\text { which part of the w } \\
\text { bonus, commission, } \\
\text { red to be in a non-pe } \\
\text { covered by a collecti } \\
N \text { their parents' level }\end{array}$ & $\begin{array}{l}\text { 18-65 working in } p \\
\text { sent sample means } \\
\text { measured in years. } \\
\text { inus } 6 \text {. Performance } \\
\text { rker's total compen } \\
\text { lece rate). Any work } \\
\text { formance-pay job. } \\
\text { e bargaining agree } \\
\text { f schooling or they }\end{array}$ & $\begin{array}{l}\text { te } \\
\text { on } \\
\text { rers } \\
\text { t. }\end{array}$ & \\
\hline
\end{tabular}


Table 2. Components of Performance Pay by Percentiles of Wage Distribution: PSID 1976-1998

\begin{tabular}{lll}
\hline \hline & Blacks & Whites \\
Percentile Range & & \\
\hline
\end{tabular}

$1-10^{\text {th }}$

$\begin{array}{ccc}\text { Piece Rates } & 0.038 & 0.013 \\ \text { Commissions } & 0.051 & 0.064 \\ \text { Bonuses } & 0.098 & 0.125\end{array}$

$11-30^{\text {th }}$

Piece Rates

0.034

0.008

Commissions

0.054

0.008

Bonuses

0.123

0.153

$31-50^{\text {th }}$

Piece Rates

Commissions

Bonuses
0.017

0.046

0.112
0.008

0.066

0.130

$51-70^{\text {th }}$

Piece Rates

0.012

0.009

Commissions

0.048

0.066

Bonuses

0.103

0.125

$71-90^{\text {th }}$

Piece Rates

Commissions

Bonuses
0.002

0.031

0.086
0.005

0.063

0.147

$91-100^{\text {th }}$

Piece Rates

Commissions

Bonuses
0.001

0.020

0.125

896

6928
0.003

0.083

0.262

2012

18330

Notes: Entries represent the fraction of observations for which the workers's pay includes either piece rates, commissions, or bonuses in any given year. 
Table 3. Effect of Variables on Black-White Wage Gap by Quantile in Performance Pay Jobs: PSID 1976-1998

\begin{tabular}{|c|c|c|c|c|c|c|c|c|c|c|c|c|}
\hline \multirow{3}{*}{$\begin{array}{l}\text { Panel A: Composition Effects } \\
\text { Total } \\
\text { (s.e.) }\end{array}$} & \multicolumn{12}{|c|}{ Quantile } \\
\hline & \multicolumn{2}{|c|}{20} & \multicolumn{2}{|c|}{50} & \multicolumn{2}{|c|}{70} & \multicolumn{2}{|c|}{80} & \multicolumn{2}{|c|}{90} & \multicolumn{2}{|c|}{95} \\
\hline & $\begin{array}{c}0.2119 \\
(0.0220)\end{array}$ & $\begin{array}{c}0.2496 \\
(0.0251)\end{array}$ & $\begin{array}{c}0.2001 \\
(0.0167)\end{array}$ & $\begin{array}{c}0.2551 \\
(0.0216)\end{array}$ & $\begin{array}{c}0.2095 \\
(0.0202)\end{array}$ & $\begin{array}{c}0.2703 \\
(0.0274)\end{array}$ & $\begin{array}{c}0.2278 \\
(0.0256)\end{array}$ & $\begin{array}{c}0.3106 \\
(0.0288)\end{array}$ & $\begin{array}{c}0.2445 \\
(0.0258)\end{array}$ & $\begin{array}{c}0.3066 \\
(0.0341)\end{array}$ & $\begin{array}{c}0.2514 \\
(0.0625)\end{array}$ & $\begin{array}{c}0.3570 \\
(0.0558)\end{array}$ \\
\hline High School Completed & $\begin{array}{c}-0.0203 \\
(0.0034)\end{array}$ & $\begin{array}{c}-0.0129 \\
(0.0042)\end{array}$ & $\begin{array}{c}-0.0132 \\
(0.0025)\end{array}$ & $\begin{array}{r}-0.0055 \\
(0.0015)\end{array}$ & $\begin{array}{c}-0.0083 \\
(0.0026)\end{array}$ & $\begin{array}{c}-0.0034 \\
(0.0013)\end{array}$ & $\begin{array}{c}-0.0110 \\
(0.0030)\end{array}$ & $\begin{array}{c}-0.0044 \\
(0.0015)\end{array}$ & $\begin{array}{c}-0.0076 \\
(0.0033)\end{array}$ & $\begin{array}{c}-0.0027 \\
(0.0015)\end{array}$ & $\begin{array}{c}-0.0061 \\
(0.0053)\end{array}$ & $\begin{array}{r}-0.0036 \\
(0.0024)\end{array}$ \\
\hline Some College & $\begin{array}{c}0.0199 \\
(0.0030)\end{array}$ & $\begin{array}{c}-0.0110 \\
(0.0042)\end{array}$ & $\begin{array}{c}0.0107 \\
(0.0020)\end{array}$ & $\begin{array}{c}-0.0058 \\
(0.0016)\end{array}$ & $\begin{array}{c}0.0111 \\
(0.0023)\end{array}$ & $\begin{array}{c}-0.0055 \\
(0.0017)\end{array}$ & $\begin{array}{c}0.0141 \\
(0.0027)\end{array}$ & $\begin{array}{c}-0.0067 \\
(0.0020)\end{array}$ & $\begin{array}{c}0.0175 \\
(0.0034)\end{array}$ & $\begin{array}{c}-0.0083 \\
(0.0025)\end{array}$ & $\begin{array}{c}0.0167 \\
(0.0047)\end{array}$ & $\begin{array}{c}-0.0088 \\
(0.0033)\end{array}$ \\
\hline B.A. or More & $\begin{array}{c}0.0509 \\
(0.0050)\end{array}$ & $\begin{array}{c}0.0305 \\
(0.0078)\end{array}$ & $\begin{array}{c}0.0608 \\
(0.0051)\end{array}$ & $\begin{array}{c}0.0352 \\
(0.0044)\end{array}$ & $\begin{array}{c}0.0810 \\
(0.0066)\end{array}$ & $\begin{array}{c}0.0464 \\
(0.0058)\end{array}$ & $\begin{array}{c}0.1149 \\
(0.0089)\end{array}$ & $\begin{array}{c}0.0658 \\
(0.0080)\end{array}$ & $\begin{array}{c}0.1365 \\
(0.0113)\end{array}$ & $\begin{array}{c}0.0783 \\
(0.0098)\end{array}$ & $\begin{array}{c}0.1436 \\
(0.0150)\end{array}$ & $\begin{array}{c}0.0837 \\
(0.0118)\end{array}$ \\
\hline Potential Experience & $\begin{array}{c}0.0039 \\
(0.0016)\end{array}$ & $\begin{array}{c}0.0817 \\
(0.0285)\end{array}$ & $\begin{array}{c}0.0108 \\
(0.0017)\end{array}$ & $\begin{array}{c}0.0461 \\
(0.0064)\end{array}$ & $\begin{array}{c}0.0164 \\
(0.0024)\end{array}$ & $\begin{array}{c}0.0774 \\
(0.0081)\end{array}$ & $\begin{array}{c}0.0266 \\
(0.0035)\end{array}$ & $\begin{array}{c}0.1303 \\
(0.0112)\end{array}$ & $\begin{array}{c}0.0364 \\
(0.0051)\end{array}$ & $\begin{array}{c}0.1716 \\
(0.0172)\end{array}$ & $\begin{array}{c}0.0453 \\
(0.0074)\end{array}$ & $\begin{array}{c}0.2124 \\
(0.0288)\end{array}$ \\
\hline Employer Tenure & $\begin{array}{c}-0.0062 \\
(0.0017)\end{array}$ & $\begin{array}{c}0.0230 \\
(0.0095)\end{array}$ & $\begin{array}{c}-0.0069 \\
(0.0019)\end{array}$ & $\begin{array}{c}0.0306 \\
(0.0028)\end{array}$ & $\begin{array}{c}-0.0073 \\
(0.0021)\end{array}$ & $\begin{array}{c}0.0305 \\
(0.0036)\end{array}$ & $\begin{array}{c}-0.0077 \\
(0.0023)\end{array}$ & $\begin{array}{c}0.0311 \\
(0.0048)\end{array}$ & $\begin{array}{c}-0.0059 \\
(0.0023)\end{array}$ & $\begin{array}{c}0.0208 \\
(0.0069)\end{array}$ & $\begin{array}{c}-0.0077 \\
(0.0035)\end{array}$ & $\begin{array}{c}0.0238 \\
(0.0116)\end{array}$ \\
\hline Married & $\begin{array}{c}0.0305 \\
(0.0043)\end{array}$ & $\begin{array}{c}0.0693 \\
(0.0172)\end{array}$ & $\begin{array}{c}0.0127 \\
(0.0038)\end{array}$ & $\begin{array}{c}0.0213 \\
(0.0056)\end{array}$ & $\begin{array}{c}0.0192 \\
(0.0048)\end{array}$ & $\begin{array}{c}0.0298 \\
(0.0071)\end{array}$ & $\begin{array}{c}0.0191 \\
(0.0062)\end{array}$ & $\begin{array}{c}0.0266 \\
(0.0091)\end{array}$ & $\begin{array}{c}0.0294 \\
(0.0086)\end{array}$ & $\begin{array}{c}0.0400 \\
(0.0127)\end{array}$ & $\begin{array}{c}0.0084 \\
(0.0143)\end{array}$ & $\begin{array}{c}0.0078 \\
(0.0208)\end{array}$ \\
\hline Covered by CBA & $\begin{array}{c}-0.0614 \\
(0.0045)\end{array}$ & $\begin{array}{c}-0.0481 \\
(0.0078)\end{array}$ & $\begin{array}{c}-0.0597 \\
(0.0047)\end{array}$ & $\begin{array}{c}-0.0391 \\
(0.0035)\end{array}$ & $\begin{array}{c}-0.0205 \\
(0.0049)\end{array}$ & $\begin{array}{c}-0.0133 \\
(0.0034)\end{array}$ & $\begin{array}{c}-0.0083 \\
(0.0057)\end{array}$ & $\begin{array}{c}-0.0060 \\
(0.0039)\end{array}$ & $\begin{array}{c}0.0077 \\
(0.0063)\end{array}$ & $\begin{array}{c}0.0031 \\
(0.0045)\end{array}$ & $\begin{array}{c}0.0002 \\
(0.0091)\end{array}$ & $\begin{array}{c}-0.0010 \\
(0.0066)\end{array}$ \\
\hline County Unemployment Rate & $\begin{array}{c}0.0005 \\
(0.0005)\end{array}$ & $\begin{array}{c}0.0038 \\
(0.0040)\end{array}$ & $\begin{array}{c}-0.0003 \\
(0.0004)\end{array}$ & $\begin{array}{c}-0.0020 \\
(0.0010)\end{array}$ & $\begin{array}{c}0.0008 \\
(0.0009)\end{array}$ & $\begin{array}{c}-0.0056 \\
(0.0015)\end{array}$ & $\begin{array}{c}-0.0014 \\
(0.0015)\end{array}$ & $\begin{array}{c}-0.0097 \\
(0.0021)\end{array}$ & $\begin{array}{c}-0.0018 \\
(0.0020)\end{array}$ & $\begin{array}{c}-0.0129 \\
(0.0029)\end{array}$ & $\begin{array}{c}-0.0023 \\
(0.0026)\end{array}$ & $\begin{array}{c}-0.0170 \\
(0.0045)\end{array}$ \\
\hline Father high school graduate & - & $\begin{array}{c}0.0063 \\
(0.0055)\end{array}$ & - & $\begin{array}{c}0.0038 \\
(0.0017)\end{array}$ & - & $\begin{array}{c}0.0003 \\
(0.0022)\end{array}$ & - & $\begin{array}{c}-0.0021 \\
(0.0029)\end{array}$ & - & $\begin{array}{c}0.0007 \\
(0.0044)\end{array}$ & - & $\begin{array}{c}0.0049 \\
(0.0070)\end{array}$ \\
\hline Mother high school graduate & - & $\begin{array}{c}0.0029 \\
(0.0053)\end{array}$ & - & $\begin{array}{c}0.0043 \\
(0.0017)\end{array}$ & - & $\begin{array}{c}0.0047 \\
(0.0022)\end{array}$ & - & $\begin{array}{l}-0.0001 \\
(0.0028)\end{array}$ & - & $\begin{array}{c}-0.0073 \\
(0.0043)\end{array}$ & - & $\begin{array}{c}-0.0001 \\
(0.0069)\end{array}$ \\
\hline Father B.A.+ & - & $\begin{array}{c}-0.0058 \\
(0.0028)\end{array}$ & - & $\begin{array}{c}-0.0020 \\
(0.0009)\end{array}$ & - & $\begin{array}{c}-0.0013 \\
(0.0009)\end{array}$ & - & $\begin{array}{c}0.0001 \\
(0.0011)\end{array}$ & - & $\begin{array}{c}-0.0004 \\
(0.0017)\end{array}$ & - & $\begin{array}{r}-0.0036 \\
(0.0033)\end{array}$ \\
\hline Mother B.A.+ & - & $\begin{array}{c}0.0059 \\
(0.0072)\end{array}$ & - & $\begin{array}{c}-0.0039 \\
(0.0020)\end{array}$ & - & $\begin{array}{c}-0.0009 \\
(0.0026)\end{array}$ & - & $\begin{array}{c}0.0081 \\
(0.0036)\end{array}$ & - & $\begin{array}{c}0.0200 \\
(0.0061)\end{array}$ & - & $\begin{array}{c}0.0140 \\
(0.0099)\end{array}$ \\
\hline Father professional & - & $\begin{array}{c}-0.0058 \\
(0.0052)\end{array}$ & - & $\begin{array}{c}-0.0011 \\
(0.0014)\end{array}$ & - & $\begin{array}{c}-0.0013 \\
(0.0019)\end{array}$ & - & $\begin{array}{c}-0.0038 \\
(0.0027)\end{array}$ & - & $\begin{array}{c}-0.0146 \\
(0.0041)\end{array}$ & - & $\begin{array}{c}-0.0212 \\
(0.0069)\end{array}$ \\
\hline Father manager & - & $\begin{array}{c}0.0106 \\
(0.0056)\end{array}$ & - & $\begin{array}{c}0.0033 \\
(0.0021)\end{array}$ & - & $\begin{array}{c}0.0129 \\
(0.0029)\end{array}$ & - & $\begin{array}{c}0.0206 \\
(0.0043)\end{array}$ & - & $\begin{array}{c}0.0144 \\
(0.0069)\end{array}$ & - & $\begin{array}{c}0.0411 \\
(0.0126)\end{array}$ \\
\hline Total Accounted for*: & $\begin{array}{c}0.2124 \\
(0.0129)\end{array}$ & $\begin{array}{c}0.2975 \\
(0.0424)\end{array}$ & $\begin{array}{c}0.2149 \\
(0.0120)\end{array}$ & $\begin{array}{c}0.2712 \\
(0.0132)\end{array}$ & $\begin{array}{c}0.2386 \\
(0.0140)\end{array}$ & $\begin{array}{c}0.3153 \\
(0.0162)\end{array}$ & $\begin{array}{c}0.2540 \\
(0.0179)\end{array}$ & $\begin{array}{c}0.3494 \\
(0.0211)\end{array}$ & $\begin{array}{c}0.3010 \\
(0.0258)\end{array}$ & $\begin{array}{c}0.3857 \\
(0.0309)\end{array}$ & $\begin{array}{c}0.3030 \\
(0.0408)\end{array}$ & $\begin{array}{c}0.3965 \\
(0.0486)\end{array}$ \\
\hline Approximation Error & $\begin{array}{c}-0.0005 \\
(0.0243)\end{array}$ & $\begin{array}{c}-0.0479 \\
(0.0303) \\
\end{array}$ & $\begin{array}{c}-0.0148 \\
(0.0179)\end{array}$ & $\begin{array}{c}-0.0161 \\
(0.0233) \\
\end{array}$ & $\begin{array}{c}-0.0291 \\
(0.0211)\end{array}$ & $\begin{array}{c}-0.0450 \\
(0.0292) \\
\end{array}$ & $\begin{array}{c}-0.0263 \\
(0.0252) \\
\end{array}$ & $\begin{array}{c}-0.0388 \\
(0.0316) \\
\end{array}$ & $\begin{array}{c}-0.0565 \\
(0.0373) \\
\end{array}$ & $\begin{array}{c}-0.0791 \\
(0.0394) \\
\end{array}$ & $\begin{array}{c}-0.0516 \\
(0.0652) \\
\end{array}$ & $\begin{array}{r}-0.0395 \\
(0.0637) \\
\end{array}$ \\
\hline
\end{tabular}


(Table 3, continued)

Panel B: Wage Structure Effects

Total

(s.e.)

High School Completed

Some College

B.A. or More

Potential Experience

Employer Tenure

Married

Covered by CBA

County Unemployment Rate

Father high school graduate

Mother high school graduate

Father B.A.+

Mother B.A.+

Father professional

Father manager

Constant

Total Accounted for:

Approximation Error
Quantile

\begin{tabular}{|c|c|c|c|c|c|c|c|c|c|c|c|}
\hline \multicolumn{2}{|c|}{20} & \multicolumn{2}{|c|}{50} & \multicolumn{2}{|c|}{70} & \multicolumn{2}{|c|}{80} & \multicolumn{2}{|c|}{90} & \multicolumn{2}{|c|}{95} \\
\hline $\begin{array}{c}0.1820 \\
(0.0442)\end{array}$ & $\begin{array}{c}0.1444 \\
(0.0452)\end{array}$ & $\begin{array}{c}0.2817 \\
(0.0288)\end{array}$ & $\begin{array}{c}0.2266 \\
(0.0318)\end{array}$ & $\begin{array}{c}0.1503 \\
(0.0259)\end{array}$ & $\begin{array}{c}0.0895 \\
(0.0311)\end{array}$ & $\begin{array}{c}0.0760 \\
(0.0286)\end{array}$ & $\begin{array}{c}0.0068 \\
(0.0312)\end{array}$ & $\begin{array}{c}0.1492 \\
(0.0385)\end{array}$ & $\begin{array}{c}0.0871 \\
(0.0363)\end{array}$ & $\begin{array}{c}0.2759 \\
(0.0568)\end{array}$ & $\begin{array}{c}0.1703 \\
(0.0493)\end{array}$ \\
\hline $\begin{array}{c}0.0752 \\
(0.0569)\end{array}$ & $\begin{array}{c}0.0811 \\
(0.0550)\end{array}$ & $\begin{array}{c}0.1191 \\
(0.0347)\end{array}$ & $\begin{array}{c}0.0941 \\
(0.0332)\end{array}$ & $\begin{array}{c}0.0435 \\
(0.0254)\end{array}$ & $\begin{array}{c}0.0297 \\
(0.0253)\end{array}$ & $\begin{array}{c}0.0467 \\
(0.0261)\end{array}$ & $\begin{array}{c}-0.0146 \\
(0.0260)\end{array}$ & $\begin{array}{c}0.0709 \\
(0.0322)\end{array}$ & $\begin{array}{c}0.0013 \\
(0.0206)\end{array}$ & $\begin{array}{c}0.0708 \\
(0.0523)\end{array}$ & $\begin{array}{c}0.0082 \\
(0.0317)\end{array}$ \\
\hline $\begin{array}{c}-0.0435 \\
(0.0285)\end{array}$ & $\begin{array}{r}-0.0525 \\
(0.0468)\end{array}$ & $\begin{array}{r}-0.0189 \\
(0.0161)\end{array}$ & $\begin{array}{c}-0.0080 \\
(0.0278)\end{array}$ & $\begin{array}{c}0.0080 \\
(0.0135)\end{array}$ & $\begin{array}{c}0.0180 \\
(0.0216)\end{array}$ & $\begin{array}{c}0.0347 \\
(0.0135)\end{array}$ & $\begin{array}{c}-0.0315 \\
(0.0160)\end{array}$ & $\begin{array}{c}0.0451 \\
(0.0168)\end{array}$ & $\begin{array}{c}0.0440 \\
(0.0211)\end{array}$ & $\begin{array}{c}0.0781 \\
(0.0266)\end{array}$ & $\begin{array}{c}0.0784 \\
(0.0322)\end{array}$ \\
\hline $\begin{array}{c}-0.0172 \\
(0.0370)\end{array}$ & $\begin{array}{c}-0.0515 \\
(0.0455)\end{array}$ & $\begin{array}{c}0.0404 \\
(0.0237)\end{array}$ & $\begin{array}{c}0.0214 \\
(0.0318)\end{array}$ & $\begin{array}{c}-0.0013 \\
(0.0224)\end{array}$ & $\begin{array}{c}0.0112 \\
(0.0299)\end{array}$ & $\begin{array}{c}0.0283 \\
(0.0225)\end{array}$ & $\begin{array}{c}-0.0129 \\
(0.0176)\end{array}$ & $\begin{array}{c}0.1542 \\
(0.0283)\end{array}$ & $\begin{array}{c}0.0880 \\
(0.0333)\end{array}$ & $\begin{array}{c}0.2966 \\
(0.0422)\end{array}$ & $\begin{array}{c}0.2550 \\
(0.0607)\end{array}$ \\
\hline-0.1364 & 0.0655 & -0.1131 & 0.1480 & -0.0374 & 0.1683 & 0.0047 & -0.2163 & 0.1497 & 0.0980 & 0.4412 & 0.3423 \\
\hline & $(0.0721)$ & & & & & $(0.0505)$ & $(0.0723)$ & $(0.0717)$ & $(0.0465)$ & $(0.1179)$ & 10.0 \\
\hline $\begin{array}{c}0.0241 \\
(0.0674)\end{array}$ & $\begin{array}{c}-0.0111 \\
(0.0555)\end{array}$ & $\begin{array}{c}0.1526 \\
(0.0363)\end{array}$ & & $\begin{array}{c}0.0718 \\
(0.0292)\end{array}$ & & $\begin{array}{c}0.0736 \\
(0.0314)\end{array}$ & $\begin{array}{c}0.0272 \\
(0.0396)\end{array}$ & $\begin{array}{c}0.1146 \\
(0.0453)\end{array}$ & $\begin{array}{c}0.0109 \\
(0.0270)\end{array}$ & $\begin{array}{l}31 \\
83)\end{array}$ & $\begin{array}{l}0 . \\
10 .\end{array}$ \\
\hline-0.0476 & 0.0274 & 0.0319 & & 0.0952 & & 0.1663 & -0.0845 & 0.2184 & & 0.1482 & 221 \\
\hline$(0.0558)$ & $(0.0523)$ & $(0.0344)$ & $(0.0331)$ & $(0.0310)$ & $(0.0300)$ & $(0.0362)$ & $(0.0393)$ & $(0.0488)$ & 10.0 & & 10. \\
\hline $\begin{array}{c}0.0290 \\
(0.0327)\end{array}$ & & & & & & & & $\begin{array}{c}-0.0121 \\
(0.0250)\end{array}$ & & & \\
\hline & & & & & & & & -0.2889 & & -0.4704 & 34 \\
\hline$(0.1181)$ & $(0.1218)$ & $(0.0649)$ & $(0.0743)$ & $(0.0546)$ & $(0.0606)$ & $(0.0632)$ & $(0.0647)$ & $(0.0809)$ & $<0.0$ & $(0.1232)$ & 10. \\
\hline- & $\begin{array}{c}0.0476 \\
(0.0712)\end{array}$ & - & $\begin{array}{c}0.0381 \\
(0.0374)\end{array}$ & - & $\begin{array}{c}-0.1036 \\
(0.0259)\end{array}$ & - & $\begin{array}{r}0.0 \\
(0.0\end{array}$ & - & & - & \\
\hline- & $\begin{array}{c}-0.0848 \\
(0.0963)\end{array}$ & - & $\begin{array}{c}-0.0126 \\
(0.0505)\end{array}$ & - & $\begin{array}{c}0.0195 \\
(0.0384)\end{array}$ & - & $\begin{array}{c}-0.0410 \\
(0.0277)\end{array}$ & - & $\begin{array}{c}0.0801 \\
(0.0398)\end{array}$ & - & $\begin{array}{c}0.2348 \\
(0.0653)\end{array}$ \\
\hline - & $\begin{array}{c}0.1140 \\
(0.0345)\end{array}$ & - & $\begin{array}{c}0.1256 \\
(0.0225)\end{array}$ & - & $\begin{array}{c}0.0571 \\
(0.0221)\end{array}$ & - & $\begin{array}{c}0.0114 \\
(0.0060)\end{array}$ & - & $\begin{array}{c}-0.0165 \\
(0.0330)\end{array}$ & - & $\begin{array}{c}-0.0618 \\
(0.0340)\end{array}$ \\
\hline- & $\begin{array}{c}0.0421 \\
(0.0127)\end{array}$ & - & $\begin{array}{c}0.0196 \\
(0.0058)\end{array}$ & - & $\begin{array}{c}0.0056 \\
(0.0043)\end{array}$ & - & $\begin{array}{c}-0.0049 \\
(0.0025)\end{array}$ & - & $\begin{array}{c}0.0049 \\
(0.0048)\end{array}$ & - & $\begin{array}{c}0.0101 \\
(0.0052)\end{array}$ \\
\hline- & $\begin{array}{c}0.0013 \\
(0.0229)\end{array}$ & - & $\begin{array}{c}0.0381 \\
(0.0128)\end{array}$ & - & $\begin{array}{c}0.0489 \\
(0.0099)\end{array}$ & - & $\begin{array}{c}-0.0342 \\
(0.0083)\end{array}$ & - & $\begin{array}{c}0.0274 \\
(0.0125)\end{array}$ & - & $\begin{array}{c}0.0359 \\
(0.0137)\end{array}$ \\
\hline- & $\begin{array}{c}0.0265 \\
(0.0071)\end{array}$ & - & $\begin{array}{c}0.0058 \\
(0.0023)\end{array}$ & - & $\begin{array}{c}0.0044 \\
(0.0018)\end{array}$ & - & $\begin{array}{c}-0.0094 \\
(0.0026)\end{array}$ & - & $\begin{array}{c}0.0071 \\
(0.0023)\end{array}$ & - & $\begin{array}{c}0.0053 \\
(0.0035)\end{array}$ \\
\hline
\end{tabular}

$\begin{array}{llllllllllll}0.1868 & -0.4725 & -0.4616 & -0.9060 & -0.0496 & -0.3763 & -0.3530 & 0.3194 & -0.0652 & 0.0749 & -0.1953 & -0.5888\end{array}$ $\begin{array}{llllllllllll}(0.3701) & (0.3766) & 0.0000 & (0.2773) & (0.2163) & (0.3239) & (0.2692) & (0.3789) & (0.2841) & (0.3346) & (0.5172) & (0.5276)\end{array}$ $\begin{array}{llllllllllll}0.1994 & 0.1749 & 0.2975 & 0.3043 & 0.1527 & 0.1269 & 0.0768 & -0.0742 & 0.1537 & 0.1230 & 0.2797 & 0.1932\end{array}$ (0.0442) $(0.0581)(0.0274)(0.0394)(0.0241)(0.0345)(0.0264)(0.0330)(0.0373)(0.0423)(0.0563)(0.0521)$

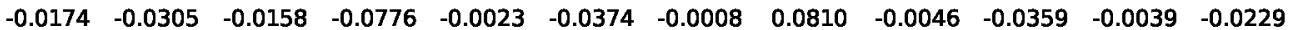
$\begin{array}{llllllllllll}(0.0205) & (0.0400) & (0.0160) & (0.0290) & (0.0126) & (0.0212) & (0.0118) & (0.0271) & (0.0107) & (0.0289) & (0.0083) & (0.0202)\end{array}$

Notes. The contribution of the covariates to the composition effects is computed using the coefficients estimated with the RIF regression methodology of Firpo et al., 2007. See text for details. *Other covariates contributing to the composition effects but not shown here are one-digit industries and occupations as well as year and census region of residence effects. Occupation effects for father are relative to all other categories, including those who never worked as well as deceased/absent fathers. 
Table 4. Effect of Variables on Black-White Wage Gap by Quantile in Non Performance Pay Jobs: PSID 1976-1998

\begin{tabular}{|c|c|c|c|c|c|c|c|c|c|c|c|c|}
\hline \multirow{3}{*}{$\begin{array}{l}\text { Panel A: Composition Effects } \\
\text { Total } \\
\text { (s.e.) }\end{array}$} & \multicolumn{12}{|c|}{ Quantile } \\
\hline & \multicolumn{2}{|c|}{20} & \multicolumn{2}{|c|}{50} & \multicolumn{2}{|c|}{70} & \multicolumn{2}{|c|}{80} & \multicolumn{2}{|c|}{90} & \multicolumn{2}{|c|}{95} \\
\hline & $\begin{array}{c}0.2181 \\
(0.0207)\end{array}$ & $\begin{array}{c}0.3314 \\
(0.0227)\end{array}$ & $\begin{array}{c}0.1374 \\
(0.0130)\end{array}$ & $\begin{array}{c}0.1906 \\
(0.0151)\end{array}$ & $\begin{array}{c}0.1186 \\
(0.0113)\end{array}$ & $\begin{array}{c}0.1574 \\
(0.0142)\end{array}$ & $\begin{array}{c}0.1050 \\
(0.0108)\end{array}$ & $\begin{array}{c}0.1496 \\
(0.0133)\end{array}$ & $\begin{array}{c}0.1228 \\
(0.0124)\end{array}$ & $\begin{array}{c}0.1679 \\
(0.0144)\end{array}$ & $\begin{array}{c}0.1250 \\
(0.0153)\end{array}$ & $\begin{array}{c}0.1701 \\
(0.0190)\end{array}$ \\
\hline High School Completed & $\begin{array}{r}-0.0043 \\
(0.0013)\end{array}$ & $\begin{array}{c}-0.0022 \\
(0.0011)\end{array}$ & $\begin{array}{c}-0.0049 \\
(0.0014)\end{array}$ & $\begin{array}{c}-0.0026 \\
(0.0012)\end{array}$ & $\begin{array}{c}-0.0027 \\
(0.0008)\end{array}$ & $\begin{array}{c}-0.0013 \\
(0.0006)\end{array}$ & $\begin{array}{c}-0.0015 \\
(0.0005)\end{array}$ & $\begin{array}{c}-0.0007 \\
(0.0004)\end{array}$ & $\begin{array}{c}-0.0012 \\
(0.0005)\end{array}$ & $\begin{array}{c}-0.0006 \\
(0.0003)\end{array}$ & $\begin{array}{l}-0.0014 \\
(0.0005)\end{array}$ & $\begin{array}{c}-0.0007 \\
(0.0014)\end{array}$ \\
\hline Some College & $\begin{array}{c}0.0024 \\
(0.0015)\end{array}$ & $\begin{array}{c}-0.0045 \\
(0.0015)\end{array}$ & $\begin{array}{c}0.0028 \\
(0.0017)\end{array}$ & $\begin{array}{c}-0.0054 \\
(0.0017)\end{array}$ & $\begin{array}{c}0.0021 \\
(0.0013)\end{array}$ & $\begin{array}{c}-0.0038 \\
(0.0012)\end{array}$ & $\begin{array}{c}0.0014 \\
(0.0009)\end{array}$ & $\begin{array}{c}-0.0025 \\
(0.0008)\end{array}$ & $\begin{array}{c}0.0007 \\
(0.0005)\end{array}$ & $\begin{array}{c}-0.0011 \\
(0.0005)\end{array}$ & $\begin{array}{c}0.0006 \\
(0.0004)\end{array}$ & $\begin{array}{c}-0.0010 \\
(0.0005)\end{array}$ \\
\hline B.A. or More & $\begin{array}{c}0.0349 \\
(0.0033)\end{array}$ & $\begin{array}{c}0.0269 \\
(0.0030)\end{array}$ & $\begin{array}{c}0.0464 \\
(0.0032)\end{array}$ & $\begin{array}{c}0.0383 \\
(0.0030)\end{array}$ & $\begin{array}{c}0.0439 \\
(0.0030)\end{array}$ & $\begin{array}{c}0.0365 \\
(0.0028)\end{array}$ & $\begin{array}{c}0.0390 \\
(0.0029)\end{array}$ & $\begin{array}{c}0.0327 \\
(0.0027)\end{array}$ & $\begin{array}{c}0.0410 \\
(0.0033)\end{array}$ & $\begin{array}{c}0.0347 \\
(0.0031)\end{array}$ & $\begin{array}{c}0.0450 \\
(0.0039)\end{array}$ & $\begin{array}{c}0.0384 \\
(0.0036)\end{array}$ \\
\hline Potential Experience & $\begin{array}{c}-0.0038 \\
(0.0012)\end{array}$ & $\begin{array}{c}-0.0068 \\
(0.0014)\end{array}$ & $\begin{array}{c}-0.0049 \\
(0.0010)\end{array}$ & $\begin{array}{c}-0.0073 \\
(0.0012)\end{array}$ & $\begin{array}{c}-0.0051 \\
(0.0009)\end{array}$ & $\begin{array}{c}-0.0070 \\
(0.0011)\end{array}$ & $\begin{array}{l}-0.0060 \\
(0.0010)\end{array}$ & $\begin{array}{c}-0.0073 \\
(0.0011)\end{array}$ & $\begin{array}{c}-0.0070 \\
(0.0012)\end{array}$ & $\begin{array}{l}-0.0078 \\
(0.0012)\end{array}$ & $\begin{array}{c}-0.0082 \\
(0.0014)\end{array}$ & $\begin{array}{c}-0.0086 \\
(0.0014)\end{array}$ \\
\hline Employer Tenure & $\begin{array}{c}-0.0074 \\
(0.0015)\end{array}$ & $\begin{array}{c}-0.0129 \\
(0.0018)\end{array}$ & $\begin{array}{l}-0.0087 \\
(0.0018)\end{array}$ & $\begin{array}{c}-0.0154 \\
(0.0020)\end{array}$ & $\begin{array}{l}-0.0079 \\
(0.0016)\end{array}$ & $\begin{array}{c}-0.0139 \\
(0.0018)\end{array}$ & $\begin{array}{c}-0.0055 \\
(0.0012)\end{array}$ & $\begin{array}{l}-0.0097 \\
(0.0014)\end{array}$ & $\begin{array}{c}-0.0038 \\
(0.0009)\end{array}$ & $\begin{array}{l}-0.0064 \\
(0.0013)\end{array}$ & $\begin{array}{c}-0.0019 \\
(0.0008)\end{array}$ & $\begin{array}{l}-0.0028 \\
(0.0012)\end{array}$ \\
\hline Married & $\begin{array}{c}0.0324 \\
(0.0032)\end{array}$ & $\begin{array}{c}0.0431 \\
(0.0040)\end{array}$ & $\begin{array}{c}0.0213 \\
(0.0023)\end{array}$ & $\begin{array}{c}0.0283 \\
(0.0029)\end{array}$ & $\begin{array}{c}0.0158 \\
(0.0019)\end{array}$ & $\begin{array}{c}0.0214 \\
(0.0024)\end{array}$ & $\begin{array}{c}0.0124 \\
(0.0017)\end{array}$ & $\begin{array}{c}0.0166 \\
(0.0022)\end{array}$ & $\begin{array}{c}0.0065 \\
(0.0019)\end{array}$ & $\begin{array}{c}0.0093 \\
(0.0025)\end{array}$ & $\begin{array}{c}0.0056 \\
(0.0021)\end{array}$ & $\begin{array}{c}0.0080 \\
(0.0029)\end{array}$ \\
\hline Covered by CBA & $\begin{array}{c}-0.0166 \\
(0.0023)\end{array}$ & $\begin{array}{c}-0.0094 \\
(0.0022)\end{array}$ & $\begin{array}{c}-0.0172 \\
(0.0024)\end{array}$ & $\begin{array}{c}-0.0096 \\
(0.0023)\end{array}$ & $\begin{array}{c}-0.0112 \\
(0.0016)\end{array}$ & $\begin{array}{c}-0.0063 \\
(0.0015)\end{array}$ & $\begin{array}{c}-0.0074 \\
(0.0012)\end{array}$ & $\begin{array}{c}-0.0041 \\
(0.0010)\end{array}$ & $\begin{array}{c}-0.0033 \\
(0.0009)\end{array}$ & $\begin{array}{c}-0.0019 \\
(0.0006)\end{array}$ & $\begin{array}{c}0.0001 \\
(0.0009)\end{array}$ & $\begin{array}{c}0.0000 \\
(0.0005)\end{array}$ \\
\hline County Unemployment Rate & $\begin{array}{c}0.0039 \\
(0.0014)\end{array}$ & $\begin{array}{c}0.0019 \\
(0.0008)\end{array}$ & $\begin{array}{c}0.0002 \\
(0.0011)\end{array}$ & $\begin{array}{c}-0.0002 \\
(0.0006)\end{array}$ & $\begin{array}{c}0.0006 \\
(0.0010)\end{array}$ & $\begin{array}{c}0.0001 \\
(0.0005)\end{array}$ & $\begin{array}{c}0.0003 \\
(0.0010)\end{array}$ & $\begin{array}{c}0.0001 \\
(0.0005)\end{array}$ & $\begin{array}{c}0.0010 \\
(0.0019)\end{array}$ & $\begin{array}{c}0.0005 \\
(0.0006)\end{array}$ & $\begin{array}{c}-0.0007 \\
(0.0013)\end{array}$ & $\begin{array}{l}-0.0003 \\
(0.0007)\end{array}$ \\
\hline Father high school graduate & - & $\begin{array}{c}0.0040 \\
(0.0012)\end{array}$ & - & $\begin{array}{c}0.0043 \\
(0.0010)\end{array}$ & - & $\begin{array}{c}0.0038 \\
(0.0009)\end{array}$ & - & $\begin{array}{c}0.0026 \\
(0.0008)\end{array}$ & - & $\begin{array}{c}0.0023 \\
(0.0010)\end{array}$ & - & $\begin{array}{c}0.0015 \\
(0.0011)\end{array}$ \\
\hline Mother high school graduate & - & $\begin{array}{c}0.0330 \\
(0.0048)\end{array}$ & - & $\begin{array}{c}0.0217 \\
(0.0038)\end{array}$ & - & $\begin{array}{c}0.0101 \\
(0.0034)\end{array}$ & - & $\begin{array}{c}0.0068 \\
(0.0033)\end{array}$ & - & $\begin{array}{c}-0.0034 \\
(0.0038)\end{array}$ & - & $\begin{array}{c}-0.0088 \\
(0.0043)\end{array}$ \\
\hline Father B.A.+ & - & $\begin{array}{c}0.0080 \\
(0.0028)\end{array}$ & - & $\begin{array}{c}0.0059 \\
(0.0024)\end{array}$ & - & $\begin{array}{c}0.0065 \\
(0.0021)\end{array}$ & - & $\begin{array}{c}0.0029 \\
(0.0021)\end{array}$ & - & $\begin{array}{c}0.0079 \\
(0.0028)\end{array}$ & - & $\begin{array}{c}0.0106 \\
(0.0037)\end{array}$ \\
\hline Mother B.A.+ & - & $\begin{array}{c}0.0026 \\
(0.0014)\end{array}$ & - & $\begin{array}{c}0.0020 \\
(0.0012)\end{array}$ & - & $\begin{array}{c}0.0000 \\
(0.0011)\end{array}$ & - & $\begin{array}{l}-0.0005 \\
(0.0011)\end{array}$ & - & $\begin{array}{c}-0.0011 \\
(0.0014)\end{array}$ & - & $\begin{array}{l}-0.0003 \\
(0.0018)\end{array}$ \\
\hline Father professional & - & $\begin{array}{c}-0.0002 \\
(0.0025)\end{array}$ & - & $\begin{array}{c}-0.0039 \\
(0.0022)\end{array}$ & - & $\begin{array}{r}-0.0074 \\
(0.0019)\end{array}$ & - & $\begin{array}{r}-0.0060 \\
(0.0019)\end{array}$ & - & $\begin{array}{c}-0.0057 \\
(0.0023)\end{array}$ & - & $\begin{array}{c}-0.0096 \\
(0.0030)\end{array}$ \\
\hline Father manager & - & $\begin{array}{c}0.0030 \\
(0.0022)\end{array}$ & - & $\begin{array}{c}0.0030 \\
(0.0018)\end{array}$ & - & $\begin{array}{c}0.0063 \\
(0.0017)\end{array}$ & - & $\begin{array}{c}0.0095 \\
(0.0018)\end{array}$ & - & $\begin{array}{c}0.0093 \\
(0.0024)\end{array}$ & - & $\begin{array}{c}0.0146 \\
(0.0032)\end{array}$ \\
\hline Total Accounted for*: & $\begin{array}{c}0.2471 \\
(0.0116)\end{array}$ & $\begin{array}{c}0.3130 \\
(0.0135)\end{array}$ & $\begin{array}{c}0.1826 \\
(0.0085)\end{array}$ & $\begin{array}{c}0.2269 \\
(0.0096)\end{array}$ & $\begin{array}{c}0.1412 \\
(0.0071)\end{array}$ & $\begin{array}{c}0.1641 \\
(0.0083)\end{array}$ & $\begin{array}{c}0.1213 \\
(0.0067)\end{array}$ & $\begin{array}{c}0.1331 \\
(0.0079)\end{array}$ & $\begin{array}{c}0.1141 \\
(0.0075)\end{array}$ & $\begin{array}{c}0.1254 \\
(0.0091)\end{array}$ & $\begin{array}{c}0.1153 \\
(0.0083)\end{array}$ & $\begin{array}{c}0.1287 \\
(0.0100)\end{array}$ \\
\hline Approximation Error & $\begin{array}{c}-0.0290 \\
(0.0224)\end{array}$ & $\begin{array}{c}0.0184 \\
(0.0251)\end{array}$ & $\begin{array}{c}-0.0452 \\
(0.0132)\end{array}$ & $\begin{array}{r}-0.0363 \\
(0.0163)\end{array}$ & $\begin{array}{l}-0.0226 \\
(0.0111)\end{array}$ & $\begin{array}{c}-0.0067 \\
(0.0145)\end{array}$ & $\begin{array}{c}-0.0163 \\
(0.0108)\end{array}$ & $\begin{array}{c}0.0166 \\
(0.0138)\end{array}$ & $\begin{array}{c}0.0086 \\
(0.0123)\end{array}$ & $\begin{array}{c}0.0424 \\
(0.0151)\end{array}$ & $\begin{array}{c}0.0097 \\
(0.0147)\end{array}$ & $\begin{array}{c}0.0414 \\
(0.0192)\end{array}$ \\
\hline
\end{tabular}


(Table 4, continued)

Panel B: Wage Structure Effects

Total

(s.e.)

High School Completed

Some College

B.A. or More

Potential Experience

Employer Tenure

Married

Covered by CBA

County Unemployment Rate

Father high school graduate

Mother high school graduate

Father B.A.+

Mother B.A.+

Father professional

Father manager

Constant

Total Accounted for:

Approximation Error
Quantile

\begin{tabular}{|c|c|c|c|c|c|c|c|c|c|c|c|}
\hline \multicolumn{2}{|c|}{20} & \multicolumn{2}{|c|}{50} & \multicolumn{2}{|c|}{70} & \multicolumn{2}{|c|}{80} & \multicolumn{2}{|c|}{90} & \multicolumn{2}{|c|}{95} \\
\hline $\begin{array}{c}0.1115 \\
(0.0436)\end{array}$ & $\begin{array}{c}0.0018 \\
(0.0442)\end{array}$ & $\begin{array}{c}0.1764 \\
(0.0234)\end{array}$ & $\begin{array}{c}0.1233 \\
(0.0245)\end{array}$ & $\begin{array}{c}0.1454 \\
(0.0175)\end{array}$ & $\begin{array}{c}0.1067 \\
(0.0193)\end{array}$ & $\begin{array}{c}0.1242 \\
(0.0157)\end{array}$ & $\begin{array}{c}0.0795 \\
(0.0171)\end{array}$ & $\begin{array}{c}0.0804 \\
(0.0148)\end{array}$ & $\begin{array}{c}0.0128 \\
(0.0133)\end{array}$ & $\begin{array}{c}0.0579 \\
(0.0175)\end{array}$ & $\begin{array}{c}0.0128 \\
(0.0203)\end{array}$ \\
\hline $\begin{array}{c}-0.1594 \\
(0.0518)\end{array}$ & $\begin{array}{c}0.2090 \\
(0.0545)\end{array}$ & $\begin{array}{c}-0.0337 \\
(0.0278)\end{array}$ & $\begin{array}{c}-0.0384 \\
(0.0303)\end{array}$ & $\begin{array}{c}-0.0042 \\
(0.0213)\end{array}$ & $\begin{array}{c}-0.0299 \\
(0.0252)\end{array}$ & & & & & $\begin{array}{c}0.0124 \\
(0.0177)\end{array}$ & \\
\hline $\begin{array}{c}-0.0414 \\
(0.0315)\end{array}$ & $\begin{array}{c}0.1048 \\
(0.0292)\end{array}$ & $\begin{array}{c}-0.0004 \\
(0.0149)\end{array}$ & $\begin{array}{c}-0.0194 \\
(0.0182)\end{array}$ & $\begin{array}{c}0.0111 \\
(0.0103)\end{array}$ & $\begin{array}{c}0.0027 \\
(0.0135)\end{array}$ & $\begin{array}{c}-0.0006 \\
(0.0084)\end{array}$ & $\begin{array}{c}-0.0071 \\
(0.0110)\end{array}$ & $\begin{array}{c}0.0006 \\
(0.0078)\end{array}$ & & & \\
\hline $\begin{array}{c}-0.0238 \\
(0.0188)\end{array}$ & $\begin{array}{c}0.0284 \\
(0.0182)\end{array}$ & $\begin{array}{c}0.0067 \\
(0.0092)\end{array}$ & $\begin{array}{c}0.0005 \\
(0.0110)\end{array}$ & $\begin{array}{c}0.0080 \\
(0.0072)\end{array}$ & $\begin{array}{c}-0.0025 \\
(0.0089)\end{array}$ & $\begin{array}{c}0.0077 \\
(0.0067)\end{array}$ & $\begin{array}{c}-0.0024 \\
(0.0080)\end{array}$ & $\begin{array}{c}0.0085 \\
(0.0068)\end{array}$ & $\begin{array}{l}-0.0006 \\
(0.0081)\end{array}$ & $\begin{array}{l}15 \\
90)\end{array}$ & $\begin{array}{l}-0 . \\
10 .\end{array}$ \\
\hline & & & & & & & & & & & \\
\hline$(0.0920)$ & $(0.0915)$ & $(0.0501)$ & $(0.0549)$ & $(0.0360)$ & 10.0 & $(0.0301)$ & $(0.04$ & $(0.02$ & 10. & 299) & 10. \\
\hline $\begin{array}{c}-0.1466 \\
(0.0357)\end{array}$ & $\begin{array}{r}0.13 \\
(0.03\end{array}$ & $\begin{array}{c}-0.0774 \\
(0.0225)\end{array}$ & $\begin{array}{c}-0.1070 \\
(0.0259)\end{array}$ & $\begin{array}{c}-0.0259 \\
(0.0174)\end{array}$ & $\begin{array}{c}-0.0425 \\
(0.0210)\end{array}$ & $\begin{array}{c}-0.0008 \\
(0.0157)\end{array}$ & $\begin{array}{c}-0.0045 \\
(0.0189)\end{array}$ & $\begin{array}{c}-0.0063 \\
(0.0162)\end{array}$ & $\begin{array}{c}-0.0106 \\
(0.0185)\end{array}$ & $\begin{array}{c}0.0051 \\
(0.0191)\end{array}$ & \\
\hline $\begin{array}{c}-0.0334 \\
(0.0583)\end{array}$ & $\begin{array}{c}0.0633 \\
(0.0587)\end{array}$ & $\begin{array}{c}0.0492 \\
(0.0298)\end{array}$ & $\begin{array}{c}0.0511 \\
(0.0305)\end{array}$ & $\begin{array}{c}0.0287 \\
(0.0214)\end{array}$ & $\begin{array}{c}0.0287 \\
(0.0227)\end{array}$ & $\begin{array}{c}0.0185 \\
(0.0189)\end{array}$ & $\begin{array}{c}0.0306 \\
(0.0193)\end{array}$ & $\begin{array}{c}0.0214 \\
(0.0168)\end{array}$ & & $\begin{array}{c}0.0189 \\
(0.0180)\end{array}$ & \\
\hline $\begin{array}{c}-0.0027 \\
(0.0296)\end{array}$ & $\begin{array}{c}0.0223 \\
(0.0304)\end{array}$ & $\begin{array}{c}-0.0442 \\
(0.0175)\end{array}$ & $\begin{array}{c}-0.0182 \\
(0.0174)\end{array}$ & $\begin{array}{c}-0.0203 \\
(0.0136)\end{array}$ & $\begin{array}{c}0.0181 \\
(0.0145)\end{array}$ & $\begin{array}{c}0.0246 \\
(0.0126)\end{array}$ & & & & & \\
\hline & & & & & & -0.0157 & & -0.0475 & -0.1087 & -0.0521 & \\
\hline$(0.1362)$ & .1293 & $(0.0577)$ & $(0.0618)$ & $(0.0426)$ & $(0.0486)$ & $(0.0386)$ & $(0.0434)$ & $(0.0381)$ & $(0.0401)$ & $(0.0449)$ & 10) \\
\hline- & $\begin{array}{l}-0.0936 \\
(0.0313)\end{array}$ & - & $\begin{array}{c}0.0413 \\
(0.0153)\end{array}$ & - & $\begin{array}{c}0.0360 \\
(0.0105)\end{array}$ & - & $\begin{array}{c}0.0448 \\
(0.0092)\end{array}$ & - & $\begin{array}{r}0.0 \\
0.0\end{array}$ & - & \\
\hline- & $\begin{array}{c}-0.0019 \\
(0.0291)\end{array}$ & - & $\begin{array}{r}-0.0125 \\
(0.0128)\end{array}$ & - & $\begin{array}{c}-0.0097 \\
(0.0092)\end{array}$ & - & $\begin{array}{c}-0.0065 \\
(0.0083)\end{array}$ & - & $\begin{array}{c}0.0142 \\
(0.0083)\end{array}$ & - & \\
\hline- & $\begin{array}{c}-0.0141 \\
(0.0082)\end{array}$ & - & $\begin{array}{c}-0.0004 \\
(0.0034)\end{array}$ & - & $\begin{array}{c}-0.0070 \\
(0.0022)\end{array}$ & - & $\begin{array}{r}-0.0066 \\
(0.0021)\end{array}$ & - & $\begin{array}{c}-0.0110 \\
(0.0020)\end{array}$ & - & $\begin{array}{c}-0.0149 \\
(0.0029)\end{array}$ \\
\hline- & $\begin{array}{c}0.0033 \\
(0.0085)\end{array}$ & - & $\begin{array}{c}-0.0002 \\
(0.0029)\end{array}$ & - & $\begin{array}{c}-0.0010 \\
(0.0025)\end{array}$ & - & $\begin{array}{c}-0.0040 \\
(0.0017)\end{array}$ & - & $\begin{array}{c}-0.0043 \\
(0.0016)\end{array}$ & - & $\begin{array}{c}-0.0079 \\
(0.0020)\end{array}$ \\
\hline- & $\begin{array}{c}-0.0013 \\
(0.0022)\end{array}$ & - & $\begin{array}{c}0.0023 \\
(0.0010)\end{array}$ & - & $\begin{array}{c}0.0019 \\
(0.0007)\end{array}$ & - & $\begin{array}{c}0.0014 \\
(0.0006)\end{array}$ & - & $\begin{array}{c}0.0014 \\
(0.0007)\end{array}$ & - & $\begin{array}{c}0.0018 \\
(0.0009)\end{array}$ \\
\hline- & $\begin{array}{c}-0.0051 \\
(0.0035)\end{array}$ & - & $\begin{array}{c}0.0020 \\
(0.0009)\end{array}$ & - & $\begin{array}{c}0.0003 \\
(0.0006)\end{array}$ & - & $\begin{array}{c}0.0014 \\
(0.0009)\end{array}$ & - & $\begin{array}{c}0.0013 \\
(0.0007)\end{array}$ & - & $\begin{array}{c}0.0014 \\
(0.0008)\end{array}$ \\
\hline
\end{tabular}

$\begin{array}{llllllllllll}0.6455 & -0.6519 & -0.0905 & -0.1917 & -0.3443 & -0.2342 & -0.3366 & -0.2230 & -0.0401 & 0.0507 & -0.0524 & -0.0421\end{array}$

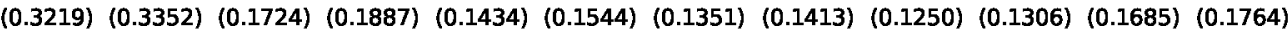
$\begin{array}{llllllllllll}0.0945 & 0.0826 & 0.1586 & 0.1214 & 0.1298 & 0.0975 & 0.1083 & 0.0666 & 0.0685 & 0.0271 & 0.0475 & 0.0051\end{array}$ (0.0436) (0.0135) $(0.0221)(0.0254)(0.0164)(0.0191)(0.0150)(0.0170)(0.0146)(0.0164)(0.0179)(0.0214)$

$\begin{array}{llllllllllll}0.0170 & -0.0808 & 0.0179 & 0.0019 & 0.0156 & 0.0092 & 0.0159 & 0.0129 & 0.0120 & 0.0083 & 0.0104 & 0.0770\end{array}$

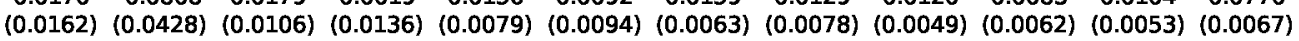

Notes. The contribution of the covariates to the composition effects is computed using the coefficients estimated with the RIF regression methodology of Firpo et al., 2007. See text for details. *Other covariates contributing to the composition effects but not shown here are one-digit industries and occupations as well as year and census region of residence effects. Occupation effects for father are relative to all other categories, including those who never worked as well as deceased/absent fathers. 
Table 5. Wage Effect of Being in a Performance Pay Job: PSID 1976-1998

\begin{tabular}{ccc} 
& Blacks & Whites \\
\hline OLS & 0.0233 & \\
& $(0.0278)$ & 0.0945 \\
Fixed-effects & 0.0295 & $(0.0151)$ \\
& $(0.0241)$ & 0.0443 \\
Number of Observations & 6928 & $(0.0137)$ \\
\hline
\end{tabular}

Standard errors in parentheses. The estimates represent the impact of being in a performance pay job controlling for the same set of covariates as those in Table 3. 
Table 6. Variance Component Models by Sectors

Subsample of workers who worked in both the public and the private sector

Panel A: Blacks

Private Sector

[1]

0.049

(0.002)

Component $\left(\sigma_{\alpha}^{2}\right)$

P-Value of Equality of

$\sigma^{2}{ }_{\alpha}$ across job types

Variance of

idiosyncratic error

\# Workers

\# Cross-Products

Panel B: Whites

0.118

(0.047)

330

15103

0.091

(0.007)

330

6628

[2]

0.064

(0.003)

0.000
Parameter

Private Sector

[1]

Variance of Worker

0.081

0.054

Component $\left(\sigma^{2}{ }_{\alpha}\right)$

(0.002)

(0.002)

P-Value of Equality of

$\sigma^{2}{ }_{\alpha}$ across sectors

Variance of

0.096

(0.005)

0.079

idiosyncratic error

501

24768

Public Sector

[2]

\# Workers

\# Cross-Products
0.000

Note: Standard errors in parentheses. These equally weighted covariance structure models are fit to the cross-products of the residuals of an OLS regression of log wages on the same set of covariates described in Table 3. 